See discussions, stats, and author profiles for this publication at: https://www.researchgate.net/publication/333477098

\title{
Determination of the oxidation state of iron in Mid-Ocean Ridge basalt glasses by Raman spectroscopy
}

Article in American Mineralogist · July 2019

DOI: 10.2138/am-2019-6887

CITATIONS

5 authors, including:

Charles Le Losq

Institut de Physique du Globe de Paris

49 PUBLICATIONS 322 CITATIONS

SEE PROFILE

Daniel Neuville

French National Centre for Scientific Research

281 PUBLICATIONS 4,915 CITATIONS

SEE PROFILE

Some of the authors of this publication are also working on these related projects:

Project $\quad \mathrm{N}$ and $\mathrm{C}$ speciation in reduced basaltic melts View project
Mark A. Kendrick

The University of Queensland

105 PUBLICATIONS 2,005 CITATIONS

SEE PROFILE 


\section{Revision 1: Determination of the oxidation state of iron in Mid-Ocean Ridge}

Charles Le Losq ${ }^{1}$, Andrew J. Berry ${ }^{1}$, Mark A. Kendrick ${ }^{1}$, Daniel R. Neuville ${ }^{2}$, Hugh St. C.

${ }^{1}$ Research School of Earth Sciences, Australian National University, Canberra, ACT 2601, Australia.

${ }^{2}$ Géomatériaux, Institut de Physique du Globe de Paris, CNRS, Paris University, Paris 75005, France.

\section{Abstract}

A series of synthetic Mid-Ocean Ridge Basalt (MORB) glasses with $\mathrm{Fe}^{3+} / \mathrm{Fe}^{\mathrm{TOT}}$ from 0 to 1 , determined previously by Mössbauer spectroscopy, was used to test methods for quantifying $\mathrm{Fe}^{3+} / \mathrm{Fe}^{\text {TOT }}$ by Raman spectroscopy. Six numerical data reduction methods were investigated, based on conventional approaches as well as supervised and unsupervised machine learning algorithms. For the set of glass standards, with fixed composition, the precision of all methods was $\leq \pm 0.04$ (one standard deviation). However, Raman spectra recorded for 42 natural MORB glasses from a wide range of locations revealed a strong correlation between the Raman spectra and composition, despite the latter varying only over a relatively limited range, such that the methods calibrated using the glass standards are not directly applicable to the natural samples. This compositional effect can be corrected by using a compositional term that links spectral variations to $\mathrm{Fe}^{3+} / \mathrm{Fe}^{\text {TOT }}$ of the glass. The resulting average $\mathrm{Fe}^{3+} / \mathrm{Fe}^{\mathrm{TOT}}$ determined by Raman spectroscopy was $0.090 \pm 0.067(n=42)$. This value agrees with the latest Fe K-edge XANES and wet-chemistry estimates of $0.10 \pm 0.02$. The larger uncertainty of the Raman determination reflects the sensitivity of Raman spectroscopy to small changes in glass structure. While this sensitivity is detrimental for high precision $\mathrm{Fe}^{3+} / \mathrm{Fe}^{\text {TOT }}$ determinations, it allows the major element composition of natural MORB glasses to be determined within $1 \mathrm{~mol} \%$ through the use of a neural network. This suggests that Raman spectrometers may be used to determine the composition of samples in situ at difficult to access locations that are incompatible with X-ray spectrometry (e.g. Mid-Ocean Ridges). Raman spectroscopy may also be useful in detecting changes in the oxidation state of Fe in volcanic glasses where high spatial resolution is required (e.g., melt inclusions), and other compositional variation is not an issue. 
Keywords: Mid-ocean ridge basalt, glass, Raman spectroscopy, iron, oxidation state, redox,

machine learning

\section{Introduction}

Mid-Ocean Ridge Basalts (MORB), derived from partial melting of the upper mantle, are central to our understanding of the geochemistry of the mantle and the formation of the oceanic crust (e.g. Langmuir et al. 1992; Asimow et al. 2004; O’Neill and Jenner 2012; Gale et al. 2013) MORB glasses, formed by rapid cooling at the rim of pillow lavas, enable the composition of the melts to be determined (e.g., Jenner and O'Neill 2012), including volatile contents (Kendrick et al. 2013), and oxidation states (Christie et al. 1986; Bézos and Humler 2005; Cottrell and Kelley 2011, 2013; Berry et al. 2018; Zhang et al. 2018; O’Neill et al. 2018). This, in turn, allows the intensive and extensive thermodynamic conditions of the mantle source to be calculated (e.g. Asimow et al. 2004). In particular, the oxidation state of $\mathrm{Fe}$ in MORB, expressed as $\mathrm{Fe}^{3+} / \mathrm{Fe}^{\mathrm{TOT}}$ with $\mathrm{Fe}^{\mathrm{TOT}}=\mathrm{Fe}^{2+}+\mathrm{Fe}^{3+}$, is important because it affects estimates of temperature, mineral assemblages, and the speciation of volatile elements, both during the production of the parental magmas in the mantle and their subsequent low-pressure evolution.

The latest average $\mathrm{Fe}^{3+} / \mathrm{Fe}^{\text {TOT }}$ values of natural MORB glasses from global sources have been determined to be $0.10 \pm 0.02$ (Berry et al. 2018) and $0.14 \pm 0.01$ (Zhang et al. 2018) by Fe Kedge XANES spectroscopy, and $0.11 \pm 0.02$ by wet-chemistry (corrected for plagioclase phenocrysts, Bézos and Humler 2005). Wet chemistry is a destructive method that lacks spatial resolution and is unsuitable for inhomogeneous glasses or small samples such as melt inclusions (e.g., see Bézos and Humler 2005). Fe K-edge XANES spectroscopy has excellent precision and micron spatial resolution in two dimensions, but requires glass standards that are compositionally matched and for which $\mathrm{Fe}^{3+} / \mathrm{Fe}^{\text {TOT }}$ has been determined by another technique, such as ${ }^{57} \mathrm{Fe}$ Mössbauer spectroscopy (e.g. Berry et al. 2008). There are also questions concerning possible photo-oxidation during analysis of hydrous glasses (e.g. Cottrell et al. 2018). A considerable drawback for routine analysis is that it requires access to a synchrotron light source.

67 Raman spectroscopy is an alternative technique for determining $\mathrm{Fe}^{3+} / \mathrm{Fe}^{\mathrm{TOT}}$ that is often readily 68 accessible without delay, is non-destructive, has micron-scale spatial resolution, requires 
minimal sample preparation, is easy to perform, and spectra can be acquired within minutes.

70 Previous studies have shown how Raman spectroscopy can be used for quantifying the concentration of $\mathrm{H}_{2} \mathrm{O}$ (Thomas 2000; Zajacz et al. 2005; Behrens et al. 2006; Thomas et al. 2008; Mercier et al. 2009, 2010; Le Losq et al. 2012) and $\mathrm{CO}_{2}$ (Amalberti et al. 2012; Morizet et al. 2013) in glasses, with applications to pumices and melt inclusions (Shea et al. 2014; Métrich et al. 2016). The potential of Raman spectroscopy to determine $\mathrm{Fe}^{3+} / \mathrm{Fe}^{\mathrm{TOT}}$ in glasses has been demonstrated previously using various data treatment protocols (Magnien et al., 2004, 2006, 2008; Roskosz et al., 2008; Di Muro et al., 2009; Di Genova et al., 2016). The simplest method requires correlating changes in $\mathrm{Fe}^{3+} / \mathrm{Fe}^{\mathrm{TOT}}$ with changes in the intensity of the Raman spectra at a given Raman shift (Magnien et al. 2006; Roskosz et al. 2008). A more complex method involves peak fitting the Raman signals assigned to stretching of tetrahedral $\mathrm{SiO}_{4}$ and $\mathrm{AlO}_{4}$ units in order to extract the $\mathrm{Fe}^{3+}-\mathrm{O}$ signal, which can be related to $\mathrm{Fe}^{3+} / \mathrm{Fe}^{\mathrm{TOT}}$ (Di Muro et al. 2009; Welsch et al. 2017). Recently, Di Genova et al. (2016) proposed another approach based on interpolation between two endmember spectra (e.g., oxidized and reduced glasses of the same composition). These different studies focused on demonstrating the ability of Raman spectroscopy to quantify $\mathrm{Fe}^{3+} / \mathrm{Fe}^{\mathrm{TOT}}$ in glasses of known composition.

Methods for quantifying $\mathrm{Fe}^{3+} / \mathrm{Fe}^{\mathrm{TOT}}$ of glasses from Raman spectra have relied on either simple treatments (e.g. the intensity of one or more peaks, mixing end-member spectra) or peak fitting. To our knowledge, machine learning algorithms, which remove subjectivity in the data reduction protocol, have not yet been tested. Here we compare existing data reduction methods (conventional methods), based on spectral intensity variations and mixing of spectra, with new supervised and unsupervised machine learning approaches. We avoided the peak fitting procedure (e.g. Di Muro et al. 2009) because it is complex to perform and equivocal of interpretation (Welsch et al. 2017), and thus may not be suited to a routine protocol.

94 Conventional methods and supervised machine learning require the $\mathrm{Fe}^{3+} / \mathrm{Fe}^{\text {TOT }}$ values of the 95 glass standards to be known. Unsupervised machine learning methods, however, do not require prior knowledge of $\mathrm{Fe}^{3+} / \mathrm{Fe}^{\mathrm{TOT}}$ of the standards, such that they offer an independent way of determining $\mathrm{Fe}^{3+} / \mathrm{Fe}^{\text {TOT }}$ for comparison with the results of other techniques. Those methods

98 were assessed for a set of 13 synthetic glasses with a typical but simplified MORB composition 99 and known $\mathrm{Fe}^{3+} / \mathrm{Fe}^{\text {TOT }}$ (Berry et al. 2018). Following the proof of concept, the methods were 100 used to determine $\mathrm{Fe}^{3+} / \mathrm{Fe}^{\text {TOT }}$ of a representative set of 42 natural MORB glasses from the 101 Atlantic, Indian and Pacific oceans, with known major and trace elements compositions 
102 (Melson et al. 2002; Jenner and O’Neill 2012; Kendrick et al. 2013) and Fe K-edge XANES

$103 \mathrm{Fe}^{3+} / \mathrm{Fe}^{\mathrm{TOT}}$ values (Berry et al. 2018).

\section{Material and Methods}

\subsection{Starting Glasses}

110 The MORB standards were prepared from mixtures of reagent grade $\mathrm{SiO}_{2}(52.0 \mathrm{wt} \%), \mathrm{Al}_{2} \mathrm{O}_{3}$ 111 (16.1 wt\%), $\mathrm{CaCO}_{3}=\mathrm{CaO}(12.4 \mathrm{wt} \%), \mathrm{Fe}_{2} \mathrm{O}_{3}=\mathrm{FeO}(10.0 \mathrm{wt} \%), \mathrm{MgO}(8.2 \mathrm{wt} \%)$ and $\mathrm{TiO}_{2}$

$112(1.3 \mathrm{wt} \%)$ that were equilibrated at $1400{ }^{\circ} \mathrm{C}$ and values of $\log f \mathrm{O}_{2}$ between 0 and $-11(-4.7$ and

1136.3 in $\log$ units relative to the quartz-fayalite-magnetite, QFM, buffer) for $\sim 24 \mathrm{~h}$ before 114 quenching in water. A sample was also prepared at $\log f \mathrm{O}_{2}=4.8(\mathrm{QFM}+11.2)$ using a piston115 cylinder apparatus. The $\mathrm{Fe}^{3+} / \mathrm{Fe}^{\mathrm{TOT}}$ ratio of each glass was determined by Mössbauer 116 spectroscopy, and found to vary from $\sim 0$ to 1 (Table 1). For further details see Berry et al. 117 (2018).

119 Samples of natural MORB glass were obtained from the Department of Mineral Sciences, 120 Smithsonian Institution, as polished chips mounted in epoxy resin and are listed by MNNH 121 catalogue numbers in Supplementary Table 1. The sample details and major element 122 composition are given in Melson et al. (2002), their trace element composition in Jenner and 123 O'Neill (2012), and their $\mathrm{Fe}^{3+} / \mathrm{Fe}^{\mathrm{TOT}}$ values determined by $\mathrm{Fe} \mathrm{K}$-edge XANES spectroscopy in 124 Berry et al. (2018). From the set analysed by Berry et al. (2018), the Raman spectra of five 125 glasses (NMNH No. 111235-85, 115083-41, 113828-5, 111241-1, 111237-67) were 126 contaminated by contributions from crystals (see supplementary code) and were not considered 127 during the data reduction. Five samples studied previously by Kendrick et al. (2013) from Juan 128 de Fuca (Alv 2262-8 and Alv 2269-2), the East Pacific Rise Clipperton (CL DR01) and Mid129 Atlantic Ridge MAPCO (CH98 DR08 and CH98 DR11) were also analysed as polished 130 sections in epoxy resin.

\subsection{Raman Spectra Acquisition}

134 Raman spectra of glasses were recorded using a Renishaw inVia ${ }^{\mathrm{TM}}$ spectrometer, equipped 135 with a Peltier-cooled detector, a 2400 1/mm grating and a confocal system. Samples were 
excited using a $532 \mathrm{~nm}$ laser line focused $\sim 3 \mu \mathrm{m}$ below the surface using a x100 Leica objective. The laser power on the sample was $\sim 1.2 \mathrm{~mW}$. The spatial resolution was $<1 \mu \mathrm{m}$, and the spectral resolution $\sim 1.2 \mathrm{~cm}^{-1}$. Five spectra were recorded from different points for each sample. They were treated separately during the data reduction process. The acquisition time varied between 120 and $180 \mathrm{~s}$. For water-bearing natural MORB samples, oxidation of Fe by the laser has been reported at high laser power (Di Genova et al. 2017). The combination of a

142 laser power less than $5 \mathrm{~mW}$ (Di Genova et al. 2017) with a relatively short counting time of

$143120 \mathrm{~s}$, and the analysis at five different spots, was used to prevent Fe oxidation during spectral

144 acquisition. We checked this by recording Raman maps for six samples, by acquiring 120 145 spectra with an acquisition time of $1 \mathrm{~s}$ over an area of $10 \mu \mathrm{m}$ by $12 \mu \mathrm{m}$. During the acquisition 146 of these maps, the sample was continuously moved, such that the beam spent less than $1 \mathrm{~s}$ at a 147 given location. The individual spectra were noisy, but their average produced a spectrum with 148 a signal to noise ratio similar to that of a spectrum acquired in $120 \mathrm{~s}$ at a single point. No 149 difference was observed between spectra obtained in these two ways, indicating that no 150 variation of $\mathrm{Fe}^{3+} / \mathrm{Fe}^{\mathrm{TOT}}$ was induced during the acquisition.

To investigate differences in spectrometer, laser wavelength, and signal-to-noise ratio $(\mathrm{S} / \mathrm{N})$, as would be expected between laboratories, spectra were also acquired using a T64000 Jobin-

154 Yvon $^{\circledR}$ Raman triple spectrometer equipped with a confocal system, a nitrogen-cooled 1024 $155 \mathrm{CCD}$ detector, and a $488 \mathrm{~nm}$ Coherent ${ }^{\circledR} 70-\mathrm{C} 5 \mathrm{Ar}^{+}$laser operating at 1.8 W. A 1/100 filter was 156 inserted in the laser pathway to ensure that laser power on the sample was less than $2 \mathrm{~mW}$ and 157 a 100x Olympus ${ }^{\circledR}$ objective was used for analysis. This setup allows a spatial resolution $<1$ $\mu \mathrm{m}$, and a spectral resolution of $\sim 0.7 \mathrm{~cm}^{-1}$. Acquisition time was tuned to deteriorate the $\mathrm{S} / \mathrm{N}$ such that, with this setup, the average $\mathrm{S} / \mathrm{N}$ in the $800-1300 \mathrm{~cm}^{-1}$ portion of the spectra was $\sim 20$, compared to over 60 for the inVia ${ }^{\mathrm{TM}}$ Renishaw system.

\subsection{Data pre-processing}

164 The spectra (Fig. 1) were pre-processed in Python using the Rampy library (Le Losq, 2018).

165 The data were corrected for temperature and excitation line effects following Galeener and Sen 166 (1978). We focused the data reduction methods on the $800-1300 \mathrm{~cm}^{-1}$ region of the spectra, 167 which contains signals from $\mathrm{Si}-\mathrm{O}, \mathrm{Al}-\mathrm{O}$ and $\mathrm{Fe}^{3+}-\mathrm{O}$ stretching in the glass structure (Brawer 168 and White 1975, 1977; Virgo et al. 1980; Mysen et al. 1982; Virgo et al. 1982). This region 
also avoided signals due to nanolites $\left(<800 \mathrm{~cm}^{-1}\right)$, which were observed in the spectra of some of the natural glasses (see supplementary materials). We chose to fit a linear baseline to subtract the background (Fig. 2A), with the aim of having only Si-O, Al-O and $\mathrm{Fe}^{3+}-\mathrm{O}$ stretching signals in the background-corrected spectra that will be used for $\mathrm{Fe}^{3+} / \mathrm{Fe}^{\mathrm{TOT}}$ determination. The low and high frequency anchors of the linear baseline were determined using a grid-search algorithm as those resulting in the lowest root mean square error (RMSE) between the Mössbauer $\mathrm{Fe}^{3+} / \mathrm{Fe}^{\text {TOT }}$ values and those predicted by the intensity and mixing methods described in sections 2.4.1 and 2.4.2. This resulted in the subtraction of a linear baseline interpolated between the intensities at 850 and $1140 \mathrm{~cm}^{-1}$ (Fig. 2A). The baseline corrected spectra were smoothed using a Whittaker function to maximize the signal to noise ratio (Eilers 2003; see supplementary code for an example), and then the intensity normalised to vary between 0 and 1 (Fig 2B). The spectra resulting from this arbitrary baseline correction cannot be used to infer the glass structure. However, the correction provides a simple method for isolating variations in the Raman signals related to changes in Fe oxidation state (Fig 2B). Furthermore, the arbitrary baseline correction was found to be beneficial because it avoids the introduction of random errors associated with variations in the real spectral background when the sample signal is low (e.g. near $1250 \mathrm{~cm}^{-1}$ ).

\subsection{Determining the oxidation state of iron by Raman spectroscopy}

In this study, six different methods were evaluated for determining the oxidation state of $\mathrm{Fe}$ in the suite of MORB glass standards (Table 1) from the background subtracted 850-1140 $\mathrm{cm}^{-1}$ region of the Raman spectra (Fig. 2B). The idea is to relate, for a set of glass standards with fixed major element composition, changes in the Raman spectra to changes in $\mathrm{Fe}^{3+} / \mathrm{Fe}^{\mathrm{TOT}}$. The six methods investigated are described below.

\subsubsection{Intensity method}

The intensity of the Raman spectra between 850 and $1140 \mathrm{~cm}^{-1}$ varies systematically with $\mathrm{Fe}^{3+} / \mathrm{Fe}^{\mathrm{TOT}}$ in the glass standards (Figs. 1, 2B). In particular, the intensity at $930 \mathrm{~cm}^{-1}$ varies strongly with $\mathrm{Fe}^{3+} / \mathrm{Fe}^{\mathrm{TOT}}$. This feature has contributions from $\mathrm{Fe}^{3+}-\mathrm{O}$ (Virgo et al. 1982; Magnien et al. 2006; Di Muro et al. 2009), and thus should be ideal for determining $\mathrm{Fe}^{3+} / \mathrm{Fe}^{\mathrm{TOT}}$. Two methods were tested to quantify the intensity at $930 \mathrm{~cm}^{-1}$ : direct measurement at fixed frequency (the average of values between 929 and $931 \mathrm{~cm}^{-1}$ ) and peak fitting the $850-1140 \mathrm{~cm}^{-}$ 
${ }^{1}$ spectral envelop with arbitrary Gaussian components. Direct measurements of the intensity

204 at $930 \mathrm{~cm}^{-1}$ (hereafter abbreviated $\mathrm{I}_{930}$ ) provided the better precision and this approach was 205 used.

\subsubsection{Mixing method}

209 The Mixing method is based on the bilinear model that describes the matrix dataset $D_{n, m}$, of

210 dimension $n$ spectra times $m$ features (i.e. Raman shifts), as:

$D_{n, m}=F_{n, k} \cdot S_{k, m}+\varepsilon_{n, m}$,

where $F_{n, k}$ is the matrix of component fractions, $S_{k, m}$ the matrix of partial spectral components

215 (endmember spectra), $k$ the number of components and $\varepsilon_{n, m}$ a noise term. In the present case,

$216 k=2$ (reduced and oxidised endmembers), as verified by a principal component analysis of the

21713 standards, which revealed that two components account for more than $99.8 \%$ of the variance

218 in the data. Using the notation $S_{\mathrm{OX}}$ and $S_{\mathrm{RED}}$ to designate the oxidised $\left(\mathrm{Fe}^{3+} / \mathrm{Fe}^{\mathrm{TOT}}=1\right)$ and

219 reduced $\left(\mathrm{Fe}^{3+} / \mathrm{Fe}^{\mathrm{TOT}}=0\right)$ Raman spectral components, and $F_{\mathrm{OX}}$ as the fraction of $S_{\mathrm{OX}}$, eq. (1)

220 can be re-arrange as:

$D_{n, m}=F_{\mathrm{OX}} \cdot S_{\mathrm{OX}}+\left(1-F_{\mathrm{OX}}\right) \cdot S_{\mathrm{RED}}$

224 We used least absolute regression (LAD) to determine $F_{\mathrm{OX}}$, because LAD is more robust than

225 least squares with respect to outliers or non-Gaussian distributions (Tarantola 2005). The 226 optimised $F_{\text {OX }}$ values can then be related to the glass $\mathrm{Fe}^{3+} / \mathrm{Fe}^{\mathrm{TOT}}$ values (Di Genova et al., 227 2016).

\subsubsection{Alternative Least Square Multivariate Curve Resolution (ALS MCR)}

231 Solving eq. (1) usually requires either $F_{n, k}$ or $S_{k, m}$. For example, $F_{n, k}$ are obtained from $S_{k, m}$ 232 in the Mixing method (sec. 2.4.2). However, several techniques allow both $F_{n, k}$ and $S_{k, m}$ to be 233 estimated from $D_{n, m}$, including independent component analysis (e.g. Hyvärinen et al. 2001), 234 non-negative matrix factorisation (e.g. Lin 2007), iterative optimisation (e.g. Zakaznova235 Herzog et al. 2007), and self-modelling curve resolution (Jiang et al. 2004; de Juan and Tauler 
2006), also known as multivariate curve resolution. As they do not require prior knowledge of neither $F_{n, k}$ nor $S_{k, m}$ (see eq. 1), those methods belong to the class of unsupervised machine learning algorithms. For the present dataset of spectra, several conditions need to be satisfied: (i) $F_{n, k} \in[0,1]$; (ii) $F_{n, 1}=1-F_{n, 2}$; and (iii) $S_{k, m} \in \mathbb{R}^{+}$. Of the available methods, multivariate curve resolution can help solve the present problem with respecting those conditions.

242 In this study, the $A L S M C R$ method was used to iteratively optimise $F_{n, k}$ and $S_{k, m}$. The PyMCR python library was used, starting the algorithm with estimations of $S_{k, m}$ obtained from mean spectra in our spectral dataset. The algorithm was allowed to perform 50 iterations. After convergence, usually achieved in only a few iterations, optimised $F_{n, k}$ and $S_{k, m}$ matrices are available for the investigated dataset. The spectral endmembers stored in the optimised $S_{k, m}$ matrix (i.e. optimised $F_{\mathrm{OX}}$ and $F_{\mathrm{RED}}$ ) can then be used with the Mixing method for new samples.

Convergence of the ALS MCR algorithm is inherently dependent on the starting conditions (e.g. Valderrama et al. 2016). The effects of the range of $\mathrm{Fe}^{3+} / \mathrm{Fe}^{\mathrm{TOT}}$ values included in $D_{n, m}$, and the starting $S_{k, m}$ components, were tested using iterative protocols. The $\mathrm{Fe}^{3+} / \mathrm{Fe}^{\text {TOT }}$ dataset range can be represented by two variables: (i) $\Delta \mathrm{Fe}^{3+} / \mathrm{Fe}^{\mathrm{TOT}}$ of $D_{n, m}$, which represents the difference in $\mathrm{Fe}^{3+} / \mathrm{Fe}^{\text {TOT }}$ between the most reduced and the most oxidized samples in the dataset; and (ii) mean $\mathrm{Fe}^{3+} / \mathrm{Fe}^{\mathrm{TOT}}$ of $D_{n, m}$, which is the mean value of $\mathrm{Fe}^{3+} / \mathrm{Fe}^{\mathrm{TOT}}$ for the dataset. Similarly, variations in the initial $S_{k, m}$ components are represented using two parameters: (i) $\Delta$ $\mathrm{Fe}^{3+} / \mathrm{Fe}^{\text {TOT }}$ of $S_{k, m}$ represents the difference in $\mathrm{Fe}^{3+} / \mathrm{Fe}^{\mathrm{TOT}}$ between the two initial $S_{k, m}$ components; and (ii) mean $\mathrm{Fe}^{3+} / \mathrm{Fe}^{\mathrm{TOT}}$ of $S_{k, m}$, which is the average $\mathrm{Fe}^{3+} / \mathrm{Fe}^{\mathrm{TOT}}$ of the two initial $S_{k, m}$ components.

To determine how the root-mean-square deviations between the estimated and nominal $\mathrm{Fe}^{3+} / \mathrm{Fe}^{\mathrm{TOT}}$ values of the standard vary with $\Delta \mathrm{Fe}^{3+} / \mathrm{Fe}^{\mathrm{TOT}}$ and mean $\mathrm{Fe}^{3+} / \mathrm{Fe}^{\mathrm{TOT}}$ of $D_{n, m}$, and $\Delta$ $\mathrm{Fe}^{3+} / \mathrm{Fe}^{\mathrm{TOT}}$ and mean $\mathrm{Fe}^{3+} / \mathrm{Fe}^{\mathrm{TOT}}$ of $S_{k, m}$, these values were varied by iteration, such that different subsets of $D_{n, m}$ and $S_{k, m}$ were generated. These subsets were provided to the $A L S$ $M C R$ algorithm to calculate optimised $S_{k, m}$ and $D_{n, m}$ matrices. These optimised matrices were then used to determine $\mathrm{Fe}^{3+} / \mathrm{Fe}^{\text {TOT }}$ for the entire $D_{n, m}$ and $S_{k, m}$ datasets. 
269 The three other techniques that were investigated used the supervised machine learning 270 regression algorithms Neural Networks, Kernel Ridge, and Support Vector from the Scikit 271 Learn library (Pedregosa et al. 2011). An interface for using these algorithms with Raman data 272 was implemented in the Rampy library (Le Losq 2018) through the class mlregressor (see the 273 Jupyter notebook in the supplementary materials as well as the rampy.mlregressor help). The 274 machine learning algorithms require the data to be divided into two subsets: a training subset 275 to train the different algorithms, and a testing subset that are treated as unknowns to evaluate 276 the predictive error of the algorithms. The train-test split was performed by randomly sorting 277 the dataset according to their $\mathrm{Fe}^{3+} / \mathrm{Fe}^{\text {TOT }}$ values (function chemical_splitting from the rampy 278 library). The testing data subset was $\sim 38 \%$ of the total dataset.

280 The Neural Network technique uses a network of activation units, which are Rectifier functions $281[y=\max (0, x)]$ (Glorot et al. 2011) in the present study, to map the relationship between the 282 Raman spectra and $\mathrm{Fe}^{3+} / \mathrm{Fe}^{\mathrm{TOT}}$ values of the glasses (see description in Bengio 2009 and 283 references therein). The activation units have adjustable parameters, called weights and biases, 284 that are optimised by least square regression. This method makes no assumptions about the 285 linearity of variations in the Raman spectra with $\mathrm{Fe}^{3+} / \mathrm{Fe}^{\mathrm{TOT}}$. The network was optimised by 286 testing different architectures to minimize the training and testing errors, and to keep those two 287 values as close as possible to each other. A simple architecture with three activation units in a 288 single hidden layer provided the most robust fits. Adding more activations units or layers did 289 not decrease the error metrics of the network, and hence this simple architecture was used. The 290 Limited-memory Broyden-Fletcher-Goldfarb-Shanno $(l b f g s)$ solver was chosen, as it performs 291 better than others for the present small dataset. Bagging, which consists of training multiple 292 networks and returning the average of their outputs (Breiman and Breiman 1996), was 293 performed to avoid over-fitting and to promote the ability of the network to predict new values.

294 A total of 100 networks were trained, and the results represent the average output of these 100 295 networks.

297 The Kernel Ridge and Support Vector techniques regress the data after their projection in a 298 high-dimensionality space. This projection was done using a non-linear radial basis kernel 299 function, such that the Raman intensity can non-linearly depend on $\mathrm{Fe}^{3+} / \mathrm{Fe}^{\mathrm{TOT}}$. The difference 300 between the Kernel Ridge and Support Vector regressions lies in the use of different loss 301 functions: Kernel Ridge regression uses a penalized ( $1_{2}$ normalisation) residual of the sum of 
squares, whereas Support Vector regression uses a $\varepsilon$-insensitive loss function ( $\varepsilon$ is a deviation term in the loss function, i.e. the predictions are allowed to be as far from the calibration data as $\varepsilon$ ). More information on these algorithms is available in Murphy (2012), Smola and Schölkopf (2004) and Vapnik (1999). The hyper-parameters of the Kernel Ridge and Support Vector algorithms were automatically tuned by performing a random 5-fold cross-validation on the training dataset.

A Jupyter notebook running under the Python language, together with all the spectra, are provided as supplementary materials to enable the results of this study, and the figures, to be reproduced.

\section{Results}

\subsection{Raman spectra of MORB glass standards}

The Raman spectra of the MORB glass standards exhibit peaks and shoulders at $\sim 505,570$,

$318660,735,804,930$ and $1005 \mathrm{~cm}^{-1}$ (A to G markers in Fig. 1), with intensities that depend on $319 \mathrm{Fe}^{3+} / \mathrm{Fe}^{\text {TOT }}$. The intensities of the $\mathrm{A}, \mathrm{B}, \mathrm{C}$ and $\mathrm{D}$ Raman signals decrease with decreasing $320 \mathrm{Fe}^{3+} / \mathrm{Fe}^{\text {TOT }}$ (Fig. 1, Table 1), whereas those of $\mathrm{E}$ and $\mathrm{G}$ increase (Figs. 1, 2B). The intensity of 321 F relative to that of $\mathrm{G}$ decreases with decreasing $\mathrm{Fe}^{3+} / \mathrm{Fe}^{\mathrm{TOT}}$ (Fig. 2B).

323 The changes in the Raman spectra of the glasses following changes in $\mathrm{Fe}^{3+} / \mathrm{Fe}^{\mathrm{TOT}}$ reflect 324 changes in (i) the $\mathrm{Fe}^{3+}$ contribution to the Raman signals, and (ii) the overall glass structure as $325 \mathrm{Fe}^{3+}$ and $\mathrm{Fe}^{2+}$ have different roles. The signals in the $810-1300 \mathrm{~cm}^{-1}$ region of the Raman 326 spectra of MORB glasses can be assigned to symmetric and asymmetric stretching of $Q^{n} \mathrm{SiO}_{4}$ $327 \mathrm{AlO}_{4}$ units, where $n$ is the number of bridging oxygens (Brawer and White 1975, 1977; 328 Furukawa and White 1980; Furukawa et al. 1981; Mysen et al. 1982; McMillan 1984; Mysen 329 1990; Neuville and Mysen 1996; Neuville et al. 2004; Neuville 2006; Neuville et al. 2008; Le 330 Losq and Neuville 2013; Le Losq et al. 2014). The intensity at F is assigned to the combination 331 of signals from $\mathrm{Fe}^{3+}-\mathrm{O}$ stretching in the glass network (Virgo et al. 1982; Wang et al. 1995; 332 Magnien et al. 2004, 2006, 2008; Di Muro et al. 2009; Cochain et al. 2012) and Si-O stretching 333 in $Q^{2}$ units (Virgo et al. 1980; Mysen et al. 1982; McMillan 1984). This assignment agrees 334 with (i) the decrease in the relative intensity of $F$ with reduction of Fe (Figs. 1, 2B) and (ii) the 
presence of $\mathrm{F}$ as a shoulder in the spectra of the most reduced samples (Figs. 1, 2B). The peak near $1005 \mathrm{~cm}^{-1}$ mainly comprises contributions from $\mathrm{Si}-\mathrm{O}$ and $\mathrm{Al}-\mathrm{O}$ stretching in $Q^{3}$ units. This signal usually occurs near $1100 \mathrm{~cm}^{-1}$ in Al-free silicate glasses (e.g. Mysen et al. 1982; McMillan 1984) but shifts to lower frequencies in aluminosilicate glasses (Neuville and Mysen 1996; Mysen et al. 2003; Le Losq and Neuville 2013). This assignment is consistent with the composition of MORB glasses; with $\mathrm{NBO} / \mathrm{T}$ values ranging from $\sim 0.5$ to $\sim 1.0$ (see Chapter 17 in Mysen and Richet 2005), they are expected to be enriched in $Q^{3}$ units and to contain minor fractions of $Q^{2}$ and $Q^{4}$ (e.g. Maekawa et al. 1991).

3.2 Raman spectroscopy as a tool for determining $\mathrm{Fe}^{3+} / \mathrm{Fe}^{T O T}$ of MORB glasses

\subsubsection{The Intensity method}

$\mathrm{I}_{930}$ in the Raman spectra of the synthetic MORB glasses is linearly correlated with $\mathrm{Fe}^{3+} / \mathrm{Fe}^{\mathrm{TOT}}$ (Fig. 3), with a correlation coefficient of 0.9973 . It is thus possible to determine $\mathrm{Fe}^{3+} / \mathrm{Fe}^{\mathrm{TOT}}$ of a glass from the I930 scaled Raman intensity using the equation:

$\mathrm{Fe}^{3+} / \mathrm{Fe}^{\mathrm{TOT}}=4.084(38) \times \mathrm{I}_{930}-2.779(29)$.

The root-mean-square deviation between the $\mathrm{Fe}^{3+} / \mathrm{Fe}^{\mathrm{TOT}}$ values of the standards and those calculated with eq. 3 is $0.02(1 \sigma)$.

\subsubsection{The Mixing method}

Following a protocol similar to that described by Di Genova et al. (2016), we used the spectra of the most oxidized and reduced glasses $\left(\log \mathrm{fO}_{2}=4.8\right.$ and -11.0 , Table 1$)$ as endmembers. Then, $F_{\mathrm{OX}}$ was adjusted by least absolute regression to obtain mixed spectra that matched the 362 observed ones (Fig. 4A). $F_{\text {OX }}$ is linearly proportional to $\mathrm{Fe}^{3+} / \mathrm{Fe}^{\mathrm{TOT}}$ (Fig. 4B) with a correlation 363 coefficient of 0.9974 . This result differs from the finding of Di Genova et al. (2016), who 364 reported non-linear variations of $F_{\mathrm{OX}}$ with $\mathrm{Fe}^{3+} / \mathrm{Fe}^{\mathrm{TOT}}$ for rhyolitic and basaltic glasses. This 365 may be due to the fact that these authors did not use endmember spectra with $\mathrm{Fe}^{3+} / \mathrm{Fe}^{\mathrm{TOT}}=0$ and 1, but of intermediate values. In the present case, $F_{\mathrm{OX}}$ and $\mathrm{Fe}^{3+} / \mathrm{Fe}^{\mathrm{TOT}}$ are related by: 
$F_{\mathrm{OX}}$ directly gives $\mathrm{Fe}^{3+} / \mathrm{Fe}^{\mathrm{TOT}}$ of MORB glasses to within $0.03(1 \sigma)$.

\subsubsection{The ALS MCR method}

For a set of glasses with unknown but varying $\mathrm{Fe}^{3+} / \mathrm{Fe}^{\text {TOT }}$ values, $A L S M C R$ can determine the endmember spectra (i.e. spectra corresponding to $\mathrm{Fe}^{3+} / \mathrm{Fe}^{\mathrm{TOT}}=0$ and 1 ), and hence, $\mathrm{Fe}^{3+} / \mathrm{Fe}^{\text {TOT }}$ for any MORB glass by linear combination fitting.

Figure 5 presents the results obtained from tests performed to evaluate the sensitivity of $A L S$ $M C R$ to the starting conditions (see sec. 2.4.3). The best results were obtained when the dataset covered the largest possible range of $\mathrm{Fe}^{3+} / \mathrm{Fe}^{\mathrm{TOT}}$ values, i.e. when $\Delta \mathrm{Fe}^{3+} / \mathrm{Fe}^{\mathrm{TOT}}$ of $D_{n, m} \rightarrow 1$ and mean $\mathrm{Fe}^{3+} / \mathrm{Fe}^{\mathrm{TOT}}$ of $D_{n, m} \rightarrow \sim 0.4-0.5$ (Fig. $5 \mathrm{~A}$ ). $\mathrm{Fe}^{3+} / \mathrm{Fe}^{\mathrm{TOT}}$ root-mean-square deviations $<0.06$ were achieved using datasets with $\Delta \mathrm{Fe}^{3+} / \mathrm{Fe}^{\text {TOT }}$ of $\mathrm{D} \geq 0.75$ and mean $\mathrm{Fe}^{3+} / \mathrm{Fe}^{\mathrm{TOT}}$ of $\mathrm{D}$ $\in[0.35,0.55]$. The choice of the initial $S_{k, m}$ affects the accuracy of the $A L S M C R$ method in a less extent than the choice of the initial $D_{n, m}$ (Fig. 5B). $\mathrm{Fe}^{3+} / \mathrm{Fe}^{\mathrm{TOT}}$ root-mean-square deviations $<0.03$ were obtained for initial $S_{k, m}$ with mean $\mathrm{Fe}^{3+} / \mathrm{Fe}^{\mathrm{TOT}} \in[0.4,0.6]$ and $\Delta \mathrm{Fe}^{3+} / \mathrm{Fe}^{\mathrm{TOT}} \in$ $[0.1,0.6]$.

The $A L S M C R$ method was tested further by optimising $S_{k, m}$ using the full dataset $D_{n, m}$. From Figure $5 \mathrm{~B}$, initial $\mathrm{S}$ components with $\Delta \mathrm{Fe}^{3+} / \mathrm{Fe}^{\mathrm{TOT}}$ and mean $\mathrm{Fe}^{3+} / \mathrm{Fe}^{\mathrm{TOT}}$ of $\sim 0.5$ and 0.4 , respectively, should provide the best results. Thus, the mean spectra at $\mathrm{Fe}^{3+} / \mathrm{Fe}^{\mathrm{TOT}}=0.66$ and 0.25 were selected as initial $S_{k, m}$ components. Selecting mean spectra with $\mathrm{Fe}^{3+} / \mathrm{Fe}^{\mathrm{TOT}}=0$ and 1 does not significantly change the results, but the present choice allows the effects of differences in the initial and optimised $S_{k, m}$ components to be illustrated, as shown in Figure $6 \mathrm{~A}$. The optimised $S_{k, m}$ spectra are clearly different from their initial values, demonstrating the ability of $A L S M C R$ to identify the true $S_{k, m}$ endmembers. The optimised $S_{k, m}$ produce good fits to the observed spectra (Fig. 6B). The fraction of the oxidised endmember, $C_{\mathrm{Ox}}$, is linearly related to the $\mathrm{Fe}^{3+} / \mathrm{Fe}^{\mathrm{TOT}}$ of the glass by (Fig. $6 \mathrm{C}$ ): 
401 Contrary to $F_{\mathrm{OX}}, C_{\mathrm{OX}}$ is not directly equal to $\mathrm{Fe}^{3+} / \mathrm{Fe}^{\mathrm{TOT}}$. This is because of small differences

402 between the optimised $S_{k, m}$ endmembers and the mean Raman spectra at $\mathrm{Fe}^{3+} / \mathrm{Fe}^{\mathrm{TOT}}=0$ and 1

403 (residuals shown in Fig. 6A). These differences introduce a bias, such that using $C_{\mathrm{OX}}$ as a direct

404 estimate of $\mathrm{Fe}^{3+} / \mathrm{Fe}^{\text {TOT }}$ leads to slightly $(\sim 0.02)$ under- and over-estimations of $\mathrm{Fe}^{3+} / \mathrm{Fe}^{\mathrm{TOT}}$,

405 depending on the $\mathrm{Fe}^{3+} / \mathrm{Fe}^{\text {TOT }}$ value. Because of this, the root-mean-square deviation between 406 the Raman-determined and standard $\mathrm{Fe}^{3+} / \mathrm{Fe}^{\text {TOT }}$ values is \pm 0.04 when assuming $F_{\mathrm{OX}}=C_{\mathrm{OXX}}$.

407 Slightly better results were obtained using eq. 5, which allows $\mathrm{Fe}^{3+} / \mathrm{Fe}^{\mathrm{TOT}}$ of the glasses to be 408 determined within \pm 0.03 (Table 1).

\subsubsection{Neural Networks, Kernel Ridge and Support Vector regression methods}

412 The Neural Network, Kernel Ridge, and Support Vector methods performed very well with 413 both the training and testing datasets (Fig. 7), with root-mean-square deviations between the 414 measured and predicted $\mathrm{Fe}^{3+} / \mathrm{Fe}^{\mathrm{TOT}}$ values of $\sim 0.01-0.03$ (Table 1). For all methods, the root415 mean-square deviations for the training dataset were slightly lower than that for the testing 416 dataset, indicating that the machine-learning algorithms tended to slightly over-fit the training 417 dataset. Over-fitting is not desirable because it indicates that the generalisation ability of the 418 algorithms (i.e. their ability to predict values for new samples) may not be optimal. However, 419 in the present case, the difference between the training and testing standard deviations is small $420(\leq 0.02)$, and the over-fitting is considered to be negligible. Therefore, these algorithms can be 421 used to predict $\mathrm{Fe}^{3+} / \mathrm{Fe}^{\mathrm{TOT}}$ of MORB glasses with an error $\leq \pm 0.03(1 \sigma)$.

\subsubsection{Is there a better method?}

The root-mean-square deviations between the $\mathrm{Fe}^{3+} / \mathrm{Fe}^{\mathrm{TOT}}$ values determined by Mössbauer and Raman spectroscopy are $<0.04$ for all six methods. The Intensity and Mixing methods are as accurate and precise as those using machine learning (ALS MCR, Neural Network, Kernel Ridge and Support Vector; Table 1).

The choice of method depends on the aims of the study and the dataset. If a single data reduction method was to be chosen, the simplicity of the Intensity and Mixing methods makes these appealing. If $\mathrm{Fe}^{3+} / \mathrm{Fe}^{\text {TOT }}$ of the standards are unknown, the $A L S M C R$ method may allow 
$433 S_{k, m}$ components to be extracted and $\mathrm{Fe}^{3+} / \mathrm{Fe}^{\mathrm{TOT}}$ to be determined, if the dataset covers a large

434 range of $\mathrm{Fe}^{3+} / \mathrm{Fe}^{\text {TOT }}$ values (Fig. 5). The Intensity, Mixing and ALS MCR methods all rely on

435 linear variations between Raman signals and $\mathrm{Fe}^{3+} / \mathrm{Fe}^{\mathrm{TOT}}$ of the glasses. In contrast, the Neural

436 Network, Kernel Ridge, and Support Vector methods do not assume linearity and do not require

437 the mathematical form of the variations to be known.

Ultimately, we recommend the use of multiple data reduction methods, as undertaken here,

441 differently sensitive to how differences in composition affect the Raman spectra (Fig. 2B).

442 Therefore, following a Bayesian approach, the average of the results from all the methods

443 should be more robust than any single estimate (e.g. Perrone 1993). In the present case, such

444 an approach is easy to implement because all the methods presented in this study are simple to

445 setup and cheap in terms of computing resources. Averaging the results of the six models to

446 determine $\mathrm{Fe}^{3+} / \mathrm{Fe}^{\text {TOT }}$ of the glasses from their Raman spectra resulted in a root-mean-square

447 deviation of $0.02(1 \sigma)$.

The baseline subtracted and normalised Raman spectra of natural MORB glasses are shown in 452 Figure 8A (see supplementary Jupyter Notebook for full spectra). While the spectra are similar 453 to that of the glass standard with $\mathrm{Fe}^{3+} / \mathrm{Fe}^{\mathrm{TOT}}=0.106$, non-negligible differences are apparent 454 (Fig. 8A). I930 varies between 0.66 and 0.76 , and is correlated with the concentration of $\mathrm{MgO}$ and $\mathrm{CaO}$ in the glass (Pearson correlation coefficient $=0.73^{\prime}$, Fig. $8 \mathrm{~B}$ ). For the glass standards, a difference of $\sim 0.10$ in $\mathrm{I}_{930}$ corresponds to a difference in $\mathrm{Fe}^{3+} / \mathrm{Fe}^{\mathrm{TOT}}$ of $\sim 0.40$ (Fig. 3). For

457 these spectra, the six methods described give an average $\mathrm{Fe}^{3+} / \mathrm{Fe}^{\mathrm{TOT}}$ of 0.15 with a large 458 standard deviation of 0.11 .

460 It is possible to refine this estimate by including a compositional term in the expressions 461 relating Raman features to $\mathrm{Fe}^{3+} / \mathrm{Fe}^{\mathrm{TOT}}$. We focused on the Intensity method and expressed I930 462 as: 
where $\mathrm{X}$ is a parameter reflecting the chemistry of the samples, and $\mathrm{K} 0, \mathrm{~K} 1$ and $\mathrm{K} 2$ constants. $\mathrm{X}$ could be chosen as either $[\mathrm{MgO}+\mathrm{CaO}]$ or the number of non-bridging oxygens per tetrahedral unit $(\mathrm{NBO} / \mathrm{T})$ in the glass. Increasing $[\mathrm{MgO}+\mathrm{CaO}]$ favours the formation of nonbridging oxygens and thus of depolymerised $Q^{2}$ units in basaltic glasses, which give signals near $950 \mathrm{~cm}^{-1}$ (e.g. Mysen et al. 1982). This is consistent with the positive trend observed between $\mathrm{I}_{930}$ and $[\mathrm{MgO}+\mathrm{CaO}]$ (Fig. $8 \mathrm{~B}$ ). However, while $\mathrm{NBO} / \mathrm{T}$ parameterises the general effect of differences in the fraction of network formers (e.g. Si, Al) and network modifiers (e.g.

$473 \mathrm{Na}, \mathrm{K}, \mathrm{Ca}, \mathrm{Mg}$ ) on the glass structure, it does not consider the effect of the ionic properties of 474 network modifiers on the distribution of $Q^{n}$ units, which contribute to the Raman intensity 475 between 850 and $1140 \mathrm{~cm}^{-1}$. For example, at a constant NBO/T of 0.5 for alkali silicate glasses, 476 the fractions of $Q^{4}$ and $Q^{2}$ increase at the expense of $Q^{3}$ as the ionic field strength $\left(Z / r^{2}\right.$, where $477 Z$ is the electric charge and $r$ the ionic radius) of the alkali metal cation increases (Maekawa et 478 al. 1991). The ionic field strength of metal cations also influences other structural properties of 479 silicate glasses and melts, including the fraction of highly-coordinated Al, excess NBO, and 480 Si-Al disorder (see Le Losq et al. 2019 for a review). As a result, to describe changes in the Raman spectra due to variations in the sample composition, we used the mean ionic field

$\operatorname{IFS}(\mathrm{M})=2 x_{\mathrm{Na}_{2} \mathrm{O}} \times \operatorname{IFS}\left(\mathrm{Na}^{+}\right)+2 x_{\mathrm{K}_{2} \mathrm{O}} \times \operatorname{IFS}\left(\mathrm{K}^{+}\right)+x_{\mathrm{CaO}} \times \operatorname{IFS}\left(\mathrm{Ca}^{2+}\right)+x_{\mathrm{MgO}} \times$

where $x_{M_{2 / Z}^{Z+} O}$ are the mol fractions of the oxide components $M_{2 / Z}^{Z+} O$, and IFS of a cation $M^{Z+}$ is calculated as $Z / r^{2}$. The $r$ values were taken from Shannon (1976) for coordination numbers (CN) of 6. For simplicity, we do not consider variations in $\mathrm{CN}$ since these are likely to be negligible given the limited range of compositional variability in MORB. We also consider $\mathrm{FeO}$ as equal to total $\mathrm{Fe}$ because $\mathrm{Fe}^{3+} / \mathrm{Fe}^{\mathrm{TOT}}$ of natural MORB is always low $(\sim 0.1)$ and constant (e.g. Berry et al. 2018; Zhang et al. 2018), such that any influence of Fe on the glass structure

The correlation between I $_{930}$ and IFS(M) is linear for natural MORB glasses (Fig. 9). The 496 ordinate at the origin of this trend corresponds to $\mathrm{K} 0+\mathrm{K} 1 \times \mathrm{Fe}^{3+} / \mathrm{Fe}^{\mathrm{TOT}}$, and its slope to $\mathrm{K} 2$. $497 \mathrm{~K} 1$ is directly given by the linear trend between $\mathrm{Fe}^{3+} / \mathrm{Fe}^{\mathrm{TOT}}$ and I930 (Fig. 3), and is equal to $4980.2435(23)$, while K2 equals $0.00624(29)$. It then is trivial to determine $\mathrm{K} 0$ as $0.111(27)$. Using 
these parameters, it is possible to plot iso-redox curves of IFS(M) versus I930, as shown in Fig. 9. A visual inspection indicates that the natural samples have a mean $\mathrm{Fe}^{3+} / \mathrm{Fe}^{\mathrm{TOT}}$ value $\sim 0.1$, although there is significant scatter. Manipulating eq. (7) to extract $\mathrm{Fe}^{3+} / \mathrm{Fe}^{\mathrm{TOT}}$ values for natural MORB from K0, K1, K2 and $\mathrm{I}_{930}$ yields a mean $\mathrm{Fe}^{3+} / \mathrm{Fe}^{\mathrm{TOT}}$ of $0.090(67)$.

\subsubsection{Effect of acquisition conditions}

Applying the methods calibrated using the spectra acquired with the Renishaw system to the spectra acquired with the T64000 Jobin-Yvon ${ }^{\circledR}$ system (see section 2.2 for details about acquisition conditions and supplementary Jupyter notebook for data visualization) resulted in the standard deviation between the Mössbauer and $\mathrm{Raman}^{\mathrm{Fe}}{ }^{3+} / \mathrm{Fe}^{\mathrm{TOT}}$ values increasing from 0.02 to 0.08 . Part of this increase in uncertainty can be assigned to the decrease in spectral $\mathrm{S} / \mathrm{N}$ (from $>60$ to $\sim 20$ ). However, $\mathrm{Fe}^{3+} / \mathrm{Fe}^{\mathrm{TOT}}$ values $>0.5$ appear to be under-estimated and have the largest effect on the average error. This may indicate that the Raman cross-sections of the $\mathrm{Si}-\mathrm{O}$ and $\mathrm{Fe}^{3+}-\mathrm{O}$ stretching modes change at different rates when varying the laser wavelength.

514 The results may also be affected by different frequency responses of the different CCD 515 detectors.

Based on those observations, it is important to record spectra with high $\mathrm{S} / \mathrm{N}(>60)$ to be able to have accurate predictions of $\mathrm{Fe}^{3+} / \mathrm{Fe}^{\mathrm{TOT}}$. Decreasing the $\mathrm{S} / \mathrm{N}$ will lead to a progressive deterioration in the precision of the predicted $\mathrm{Fe}^{3+} / \mathrm{Fe}^{\mathrm{TOT}}$ values. If different spectrometers and laser wavelengths are used, the accuracy of any previously calibrated algorithms should be checked using standards.

\section{Discussion}

Both conventional methods (Intensity, Mixing) and machine learning algorithms (ALS MCR, Kernel Ridge, Support Vector and Neural Network) allow $\mathrm{Fe}^{3+} / \mathrm{Fe}^{\mathrm{TOT}}$ to be determined from the Raman spectra of glasses, with fixed major element composition, with uncertainties $<0.04$

528 (Table 1). The combination of all six methods gives a precision of 0.02 . The Intensity and 529 Mixing methods are simple and provide accurate results. The machine learning methods 530 performed well despite being trained with a limited set of samples. The ALS MCR method may 531 be useful if the $\mathrm{Fe}^{3+} / \mathrm{Fe}^{\text {TOT }}$ values of the glass standards are unknown, or if endmember spectra 532 are not available. Kernel Ridge, Support Vector and Neural Network regression algorithms 
533 relate $\mathrm{Fe}^{3+} / \mathrm{Fe}^{\text {TOT }}$ of the glasses to variations in their Raman spectra without any assumptions

534 about the form of the variations. Pooling the results from multiple data reduction protocols is 535 recommended for maximizing the robustness of $\mathrm{Fe}^{3+} / \mathrm{Fe}^{\mathrm{TOT}}$ determinations for glasses with a

536 fixed composition.

538 The determination of $\mathrm{Fe}^{3+} / \mathrm{Fe}^{\mathrm{TOT}}$ in natural MORB glasses requires a correction for the effect 539 of composition on the Raman spectra (Figs. 8B, 9, eq. 7). The corrected mean value of $540 \mathrm{Fe}^{3+} / \mathrm{Fe}^{\mathrm{TOT}}=0.090(67)$ is in agreement with the latest XANES and wet chemistry results 541 (Bézos and Humler 2005; Berry et al. 2018; Zhang et al. 2018). In particular, this estimate is 542 in close agreement with the XANES value of 0.10(1) reported by Berry et al. (2018) for the 543 same set of samples, which suggests an average $\mathrm{fO}_{2}$ for MORB of 0.1 log units above the QFM 544 redox buffer.

546 Raman spectroscopy can thus provide reasonable estimates of $\mathrm{Fe}^{3+} / \mathrm{Fe}^{\mathrm{TOT}}$ in glasses, as long as 547 the effect of glass chemistry is considered. High precision can be achieved for laboratory 548 samples with constant chemical composition. However, the present results do not achieve the 549 precision of Fe K-edge XANES, Mössbauer spectroscopy or wet chemistry for natural samples 550 with variable chemical composition without the introduction of a compositional term. 551 Compositional effects originating from variations in major element concentrations were 552 corrected using eq. (6), but other factors that affect glass structure (and hence the Raman 553 spectra), such as volatile content and quench rate, were not considered. The high standard 554 deviation affecting the $\mathrm{Fe}^{3+} / \mathrm{Fe}^{\mathrm{TOT}}$ estimate most probably reflects the occurrence of such 555 effects. Further, while eq. (6) is valid for MORB glasses, it may not be suitable for determining $556 \mathrm{Fe}^{3+} / \mathrm{Fe}^{\text {TOT }}$ in other compositions. However, with a set of appropriate standards, Raman 557 spectroscopy could be used to quantify $\mathrm{Fe}^{3+} / \mathrm{Fe}^{\mathrm{TOT}}$ in any composition. In all cases, the routine 558 determination of $\mathrm{Fe}^{3+} / \mathrm{Fe}^{\text {TOT }}$ in natural samples by Raman spectroscopy will be challenging due 559 to the many variables that affect glass structure.

\section{Implications}

563 Machine learning techniques do not seem to be advantageous relative to conventional 564 approaches for quantifying $\mathrm{Fe}^{3+} / \mathrm{Fe}^{\text {TOT }}$ in glasses with constant composition by Raman 565 spectroscopy. However, their ease of implementation and flexibility (the problem can be non566 linear) make them preferable to other user-defined techniques when the functional form of the 
567 problem is unknown. In particular, the sensitivity of Raman spectra to glass structure can be 568 used to determine glass composition. Di Genova et al. $(2015 ; 2016)$ used the mixing method 569 to determine the composition of natural glasses from Raman spectra. This required a post570 analysis step in the data treatment as the mixing ratio of end-member spectra varied non571 linearly with glass composition. In the present case, we trained a neural network to directly 572 link the corrected $850-1140 \mathrm{~cm}^{-1}$ Raman signals (Fig. 8A) to the measured concentrations of major elements in the natural MORB glasses (supplementary materials), without any additional

574 data manipulation. The results from one of the trained neural networks are shown in Figure 10.

575 The network was able to predict the chemistry of MORB glasses with errors $<\sim 1 \mathrm{~mol} \%$. This

576 result suggests that Raman spectroscopy may be developed as a chemical probe. It also 577 demonstrates the usefulness of neural networks for such calculations, as the algorithm directly 578 provides the glass composition without intermediate data analysis steps. The approach could 579 allow Raman spectroscopy to be used in situ to analyse pillow lavas with glassy rims at ocean 580 ridges, by using submersibles equipped with Raman spectrometers already developed for deep 581 sea water analysis (e.g. Brewer et al. 2004; White et al. 2005; Du et al. 2015). Raman 582 spectrometers could also be used as a chemical probe in missions to planets or moons with 583 dense atmospheres. The fact that all data processing performed in this study uses Python, a 584 programming language that can be easily used in embedded systems would facilitate uptake.

585 The present approach should be easy to implement for any system operating a portable Raman spectrometer.

\section{Acknowledgement}

The Department of Mineral Sciences, Smithsonian Institution, is thanked for providing the samples of MORB glass. H.O.N thanks the Australian Research Council for the award of a

592 Laureate Fellowship (FL130100066). C.L.L. thanks Guil Mallmann for helpful discussions.

593 The authors thank an anonymous reviewer for helpful comments.

\section{References} for geodynamics. Mineralogical Magazine, 76. 
600

601

602

603

604

605

606

607

608

609

610

611

612

613

614

615

616

617

618

619

620

621

Asimow, P.D., Dixon, J.E., and Langmuir, C.H. (2004) A hydrous melting and fractionation model for mid-ocean ridge basalts: Application to the Mid-Atlantic Ridge near the Azores. Geochemistry, Geophysics, Geosystems, 5.

Behrens, H., Roux, J., Neuville, D., and Siemann, M. (2006) Quantification of dissolved $\mathrm{H}_{2} \mathrm{O}$ in silicate glasses using confocal microRaman spectroscopy. Chemical Geology, 229, 96-112.

Bengio, Y. (2009) Learning Deep Architectures for AI. Foundations and Trends ${ }^{\circledR}$ in Machine Learning, 2, 1-127.

Berry, A.J., Danyushevsky, L.V., O’Neill, H.S.C., Newville, M., and Sutton, S.R. (2008) Oxidation state of iron in komatiitic melt inclusions indicates hot Archaean mantle. Nature, 455, 960-963.

Berry, A.J., Stewart, G.A., O’Neill, H.S.C., Mallmann, G., and Mosselmans, J.F.W. (2018) A re-assessment of the oxidation state of iron in MORB glasses. Earth and Planetary Science Letters, 483, 114-123.

Bézos, A., and Humler, E. (2005) The $\mathrm{Fe}^{3+} / \Sigma \mathrm{Fe}$ ratios of MORB glasses and their implications for mantle melting. Geochimica et Cosmochimica Acta, 69, 711-725.

Brawer, S.A., and White, W.B. (1975) Raman spectroscopic investigation of the structure of silicate glasses. I. The binary alkali silicates. The Journal of Chemical Physics, 63, $2421-2432$.

(1977) Raman spectroscopic investigation of the structure of silicate glasses (II). Soda-alkaline earth-alumina ternary and quaternary glasses. Journal of NonCrystalline Solids, 23, 261-278.

Breiman, L., and Breiman, L. (1996) Bagging Predictors. In Machine Learning pp. 123-140.

Brewer, P.G., Malby, G., Pasteris, J.D., White, S.N., Peltzer, E.T., Wopenka, B., Freeman, J., and Brown, M.O. (2004) Development of a laser Raman spectrometer for deep-ocean science. Deep Sea Research Part I: Oceanographic Research Papers, 51, 739-753.

Christie, D.M., Carmichael, I.S.E., and Langmuir, C.H. (1986) Oxidation states of mid-ocean ridge basalt glasses. Earth and Planetary Science Letters, 79, 397-411.

Cochain, B., Neuville, D.R., Henderson, G.S., McCammon, C.A., Pinet, O., and Richet, P. (2012) Effects of the iron content and redox state on the structure of sodium borosilicate glasses: A Raman, Mössbauer and boron K-Edge XANES spectroscopy study. Journal of the American Ceramic Society, 95, 962-971.

Cottrell, E., and Kelley, K.A. (2011) The oxidation state of Fe in MORB glasses and the oxygen fugacity of the upper mantle. Earth and Planetary Science Letters, 305, 270282.

(2013) Redox heterogeneity in mid-ocean ridge basalts as a function of mantle source. Science, 340, 1314-1317. 
Cottrell, E., Lanzirotti, A., Mysen, B.O., Birner, S., Kelley, K.A., Botcharnikov, R.E., Davis, F.A., and Newville, M. (2018) A Mössbauer-based XANES calibration for hydrous basalt glasses reveals radiation-induced oxidation of Fe. American Mineralogist, 103, 489-501.

de Juan, A., and Tauler, R. (2006) Multivariate Curve Resolution (MCR) from 2000:

Progress in Concepts and Applications. Critical Reviews in Analytical Chemistry, 36, $163-176$.

Di Genova, D., Morgavi, D., Hess, K.-U., Neuville, D.R., Borovkov, N., Perugini, D., and Dingwell, D.B. (2015) Approximate chemical analysis of volcanic glasses using Raman spectroscopy. Journal of Raman Spectroscopy, 46, 1235-1244.

Di Genova, D., Hess, K.-U., Chevrel, M.O., and Dingwell, D.B. (2016) Models for the estimation of $\mathrm{Fe}^{3+} / \mathrm{Fe}^{\text {tot }}$ ratio in terrestrial and extraterrestrial alkali- and iron-rich silicate glasses using Raman spectroscopy. American Mineralogist, 101, 943-952.

Di Genova, Danilo, Kolzenburg, S., Vona, A., Chevrel, M.O., Hess, K.-U., Neuville, D.R., Ertel-Ingrisch, W., Romano, C., and Dingwell, D.B. (2016) Raman spectra of Martian glass analogues: A tool to approximate their chemical composition. Journal of Geophysical Research: Planets, 121, 2016JE005010.

Di Genova, D., Sicola, S., Romano, C., Vona, A., Fanara, S., and Spina, L. (2017) Effect of iron and nanolites on Raman spectra of volcanic glasses: A reassessment of existing strategies to estimate the water content. Chemical Geology, 475, 76-86.

Di Muro, A., Métrich, N., Mercier, M., Giordano, D., Massare, D., and Montagnac, G. (2009) Micro-Raman determination of iron redox state in dry natural glasses: Application to peralkaline rhyolites and basalts. Chemical Geology, 259, 78-88.

Du, Z., Li, Y., Chen, J., Guo, J., and Zheng, R. (2015) Feasibility investigation on deep ocean compact autonomous Raman spectrometer developed for in-situ detection of acid radical ions. Chinese Journal of Oceanology and Limnology, 33, 545-550.

Eilers, P.H.C. (2003) A perfect smoother. Analytical Chemistry, 75, 3631-3636.

Furukawa, T., and White, W.B. (1980) Vibrational spectra and glass structure. Journal of Non-Crystalline Solids, 38, 87-92.

Furukawa, T., Fox, K.E., and White, W.B. (1981) Raman spectroscopic investigation of the structure of silicate glasses. III. Raman intensities and structural units in sodium silicate glasses. The Journal of Chemical Physics, 75, 3226-3237.

Gale, A., Dalton, C.A., Langmuir, C.H., Su, Y., and Schilling, J.-G. (2013) The mean composition of ocean ridge basalts. Geochemistry, Geophysics, Geosystems, 14, 489518.

Galeener, F.L., and Sen, P.N. (1978) Theory of the first-order vibrational spectra of disordered solids. Physical Review B, 17, 1928-1933.

Glorot, X., Bordes, A., and Bengio, Y. (2011) Deep sparse rectifier neural networks. In International Conference on Artificial Intelligence and Statistics pp. 315-323. 
Hyvärinen, A., Karhunen, J., and Oja, E. (2001) Independent component analysis. John Wiley \& Sons, Inc.

Jenner, F.E., and O'Neill, H.S.C. (2012) Analysis of 60 elements in 616 ocean floor basaltic glasses: TECHNICAL BRIEF. Geochemistry, Geophysics, Geosystems, 13, Q02005.

Jiang, J.-H., Liang, Y., and Ozaki, Y. (2004) Principles and methodologies in self-modeling curve resolution. Chemometrics and Intelligent Laboratory Systems, 71, 1-12.

Kendrick, M.A., Arculus, R., Burnard, P., and Honda, M. (2013) Quantifying brine assimilation by submarine magmas: Examples from the Galápagos Spreading Centre and Lau Basin. Geochimica et Cosmochimica Acta, 123, 150-165.

Langmuir, C.H., Klein, E.M., and Plank, T. (1992) Petrological Systematics of Mid-Ocean Ridge Basalts: Constraints on Melt Generation Beneath Ocean Ridges. In Mantle Flow and Melt Generation at Mid-Ocean Ridges pp. 183-280. American Geophysical Union (AGU).

Le Losq, C. (2018) Rampy: a Python library for processing spectroscopic (IR, Raman, XAS...) data. Zenodo.

Le Losq, C., and Neuville, D.R. (2013) Effect of the $\mathrm{Na} / \mathrm{K}$ mixing on the structure and the rheology of tectosilicate silica-rich melts. Chemical Geology, 346, 57-71.

Le Losq, C., Neuville, D.R., Moretti, R., and Roux, J. (2012) Determination of water content in silicate glasses using Raman spectrometry: Implications for the study of explosive volcanism. American Mineralogist, 97, 779-790.

Le Losq, C., Neuville, D.R., Florian, P., Henderson, G.S., and Massiot, D. (2014) The role of $\mathrm{Al}^{3+}$ on rheology and structural changes of sodium silicate and aluminosilicate glasses and melts. Geochimica et Cosmochimica Acta, 126, 495-517.

Le Losq, C., Cicconi, M.R., Greaves, G.N., and Neuville, D.R. (2019) Silicate Glasses. In Handbook of Glass. Springer.

Lin, C.-J. (2007) Projected Gradient Methods for Nonnegative Matrix Factorization. Neural Computation, 19, 2756-2779.

Maekawa, H., Maekawa, T., Kawamura, K., and Yokokawa, T. (1991) The structural groups of alkali silicate glasses determined from ${ }^{29} \mathrm{Si}$ MAS-NMR. Journal of Non-Crystalline Solids, 127, 53-64.

Magnien, V., Neuville, D.R., Cormier, L., Mysen, B.O., Briois, V., Belin, S., Pinet, O., and Richet, P. (2004) Kinetics of iron oxidation in silicate melts: a preliminary XANES study. Chemical Geology, 213, 253-263.

Magnien, V., Neuville, D.R., Cormier, L., Roux, J., Hazemann, J.L., Pinet, O., and Richet, P. (2006) Kinetics of iron redox reactions in silicate liquids: A high-temperature X-ray absorption and Raman spectroscopy study. Journal of Nuclear Materials, 352, 190195. 
Magnien, V., Neuville, D., Cormier, L., Roux, J., Hazemann, J., Deligny, D., Pascarelli, S., Vickridge, I., Pinet, O., and Richet, P. (2008) Kinetics and mechanisms of iron redox reactions in silicate melts: The effects of temperature and alkali cations. Geochimica et Cosmochimica Acta, 72, 2157-2168.

McMillan, P.F. (1984) Structural studies of silicate glasses and melts - Applications and limitations of Raman spectroscopy. American Mineralogist, 69, 622-644.

Melson, W.G., O'Hearn, T., and Jarosewich, E. (2002) A data brief on the Smithsonian Abyssal Volcanic Glass Data File. Geochemistry, Geophysics, Geosystems, 3, 1-11.

Mercier, M., Di Muro, A., Giordano, D., Métrich, N., Lesne, P., Pichavant, M., Scaillet, B., Clocchiatti, R., and Montagnac, G. (2009) Influence of glass polymerisation and oxidation on micro-Raman water analysis in alumino-silicate glasses. Geochimica et Cosmochimica Acta, 73, 197-217.

Mercier, M., Muro, A.D., Métrich, N., Giordano, D., Belhadj, O., and Mandeville, C.W. (2010) Spectroscopic analysis (FTIR, Raman) of water in mafic and intermediate glasses and glass inclusions. Geochimica et Cosmochimica Acta, 74, 5641-5656.

Métrich, N., Bertagnini, A., Garaebiti, E., Vergniolle, S., Bani, P., Beaumais, A., and Neuville, D.R. (2016) Magma transfer and degassing budget: Application to the 2009-2010 eruptive crisis of Mt Garet (Vanuatu arc). Journal of Volcanology and Geothermal Research, 322, 48-62.

Morizet, Y., Brooker, R.A., Iacono-Marziano, G., and Kjarsgaard, B.A. (2013) Quantification of dissolved $\mathrm{CO}_{2}$ in silicate glasses using micro-Raman spectroscopy. American Mineralogist, 98, 1788-1802.

Murphy, K.P. (2012) Machine Learning: A Probabilistic Perspective. The MIT Press, Cambridge, Massachusetts.

Mysen, B.O. (1990) Role of $\mathrm{Al}$ in depolymerized, peralkaline aluminosilicate melts in the systems $\mathrm{Li}_{2} \mathrm{O}-\mathrm{Al}_{2} \mathrm{O}_{3}-\mathrm{SiO}_{2}, \mathrm{Na}_{2} \mathrm{O}-\mathrm{Al}_{2} \mathrm{O}_{3}-\mathrm{SiO}_{2}$, and $\mathrm{K}_{2} \mathrm{O}-\mathrm{Al}_{2} \mathrm{O}_{3}-\mathrm{SiO}_{2}$. American Mineralogist, 75, 120-134.

Mysen, B.O., and Richet, P. (2005) Silicate glasses and melts - Properties and structure Vol. 10. Elsevier B.V., Amsterdam.

Mysen, B.O., Finger, L.W., Virgo, D., and Seifert, F.A. (1982) Curve-fitting of Raman spectra of silicate glasses. American Mineralogist, 67, 686-695.

Mysen, B.O., Lucier, A., and Cody, G.D. (2003) The structural behavior of $\mathrm{Al}^{3+}$ in peralkaline melts and glasses in the system $\mathrm{Na}_{2} \mathrm{O}-\mathrm{Al}_{2} \mathrm{O}_{3}-\mathrm{SiO}_{2}$. American Mineralogist, $88,1668-1678$.

Neuville, D.R. (2006) Viscosity, structure and mixing in (Ca, Na) silicate melts. Chemical Geology, 229, 28-41.

Neuville, D.R., and Mysen, B.O. (1996) Role of aluminium in the silicate network: In situ, high-temperature study of glasses and melts on the join $\mathrm{SiO}_{2}-\mathrm{NaAlO}_{2}$. Geochimica et Cosmochimica Acta, 60, 1727-1737. 
Neuville, D.R., Cormier, L., and Massiot, D. (2004) Al environment in tectosilicate and peraluminous glasses: A ${ }^{27} \mathrm{Al}$ MQ-MAS NMR, Raman, and XANES investigation. Geochimica et Cosmochimica Acta, 68, 5071-5079.

Neuville, D.R., Cormier, L., Montouillout, V., Florian, P., Millot, F., Rifflet, J.-C., and Massiot, D. (2008) Structure of Mg- and $\mathrm{Mg} / \mathrm{Ca}$ aluminosilicate glasses: ${ }^{27} \mathrm{Al} \mathrm{NMR}$ and Raman spectroscopy investigations. American Mineralogist, 93, 1721-1731.

O'Neill, H.S.C., and Jenner, F.E. (2012) The global pattern of trace-element distributions in ocean floor basalts. Nature, 491, 698-704.

O'Neill, H.S.C., Berry, A.J., and Mallmann, G. (2018) The oxidation state of iron in MidOcean Ridge basaltic (MORB) glasses: implications for their petrogenesis and oxygen fugacities. Earth and Planetary Science Letters, 504, 152-162.

Pedregosa, F., Varoquaux, G., Gramfort, A., Michel, V., Thirion, B., Grisel, O., Blondel, M., Prettenhofer, P., Weiss, R., Dubourg, V., and others (2011) Scikit-learn: machine learning in python. Journal of Machine Learning Research, 12, 2825-2830.

Perrone, M.P. (1993) Improving regression estimation: Averaging methods for variance reduction with extensions to general convex measure optimization. Brown University Providence, RI.

Roskosz, M., Toplis, M.J., Neuville, D.R., and Mysen, B.O. (2008) Quantification of the kinetics of iron oxidation in silicate melts using Raman spectroscopy and assessment of the role of oxygen diffusion. American Mineralogist, 93, 1749-1759.

Shannon, R.D. (1976) Revised effective ionic radii and systematic studies of interatomic distances in halides and chalcogenides. Acta Crystallographica Section A: Crystal Physics, Diffraction, Theoretical and General Crystallography, 32, 751-767.

Shea, T., Hellebrand, E., Gurioli, L., and Tuffen, H. (2014) Conduit- to Localized-scale Degassing during Plinian Eruptions: Insights from Major Element and Volatile $(\mathrm{Cl}$ and $\mathrm{H}_{2} \mathrm{O}$ ) Analyses within Vesuvius AD 79 Pumice. Journal of Petrology, 55, 315344.

Smola, A. J., and Schölkopf, B. (2004) A tutorial on support vector regression. Statistics and Computing, 14, 199-222.

Tarantola, A. (2005) Inverse problem theory and methods for model parameter estimation, 342 p. Society for Industrial and Applied Mathematics, Philadelphia, PA.

Thomas, R. (2000) Determination of water contents of granite melt inclusions by confocal laser Raman microprobe spectroscopy. American Mineralogist, 85, 868-872.

Thomas, R., Metrich, N., Scaillet, B., Kamenetsky, V.S., and Davidson, P. (2008) Determination of water in Fe-rich basalt glasses with confocal micro-Raman spectroscopy. Zeitschrift für Geologische Wissenschaften, 36, 31-37.

Valderrama, L., Gonçalves, R.P., Março, P.H., Rutledge, D.N., and Valderrama, P. (2016) Independent components analysis as a means to have initial estimates for multivariate curve resolution-alternating least squares. Journal of Advanced Research, 7, 795-802. 
Vapnik, V., V. (1999) The Nature of Statistical Learning Theory, Second Edition., 332 p. Springer-Verlag, New York.

Virgo, D., Mysen, B.O., and Kushiro, I. (1980) Anionic constitution of 1-Atmosphere silicate melts: implications for the structure of igneous melts. Science, 208, 1371-1373.

Virgo, D., Mysen, B. O., Danckwerth, P., and Seifert, F. (1982) Speciation of $\mathrm{Fe}^{3+}$ in 1-atm

Wang, Z., Cooney, T.F., and Sharma, S.K. (1995) In situ structural investigation of iron$\mathrm{Na}_{2} \mathrm{O}-\mathrm{SiO}_{2}-\mathrm{Fe}-\mathrm{O}$ Melts. Carnegie Institution of Washington Year Book, 81, 349-353. containing silicate liquids and glasses. Geochimica et Cosmochimica Acta, 59, 15711577.

Welsch, A.-M., Knipping, J.L., and Behrens, H. (2017) Fe-oxidation state in alkali-trisilicate glasses - A Raman spectroscopic study. Journal of Non-Crystalline Solids, 471, 28 38 .

White, S.N., Kirkwood, W., Sherman, A., Brown, M., Henthorn, R., Salamy, K., Walz, P., Peltzer, E.T., and Brewer, P.G. (2005) Development and deployment of a precision underwater positioning system for in situ laser Raman spectroscopy in the deep ocean. Deep Sea Research Part I: Oceanographic Research Papers, 52, 2376-2389.

Zakaznova-Herzog, V.P., Malfait, W.J., Herzog, F., and Halter, W.E. (2007) Quantitative Raman spectroscopy: Principles and application to potassium silicate glasses. Journal of Non-Crystalline Solids, 353, 4015-4028.

Zhang, H.L., Cottrell, E., Solheid, P.A., Kelley, K.A., and Hirschmann, M.M. (2018) spectroscopy and its application to the oxidation state of iron in MORB. Chemical Geology, 479, 166-175. 
820 Table 1: Synthesis oxygen fugacity at $1400{ }^{\circ} \mathrm{C}$, and relative to the quartz-fayalite-magnetite 821 (QFM) buffer, of MORB glass standards (Berry et al. 2018), together with the $\mathrm{Fe}^{3+} / \mathrm{Fe}^{\text {TOT }}$ 822 values determined by Mössbauer spectroscopy $( \pm 0.01)$, and by Raman spectroscopy using the 823 Intensity (Int.), Mixing (Mix.), ALS MCR (A.M.), Neural Networks (N.N.), Kernel Ridge 824 (K.R.) and Support Vector (S.V.) techniques. Root-mean-squared deviations (RMSD, 1 $\sigma$ ) of 825 the different Raman methods are indicated at the bottom; *calculated for the training data 826 subset; ${ }^{\phi}$ calculated for the testing data subset.

827

\begin{tabular}{|c|c|c|c|c|c|c|c|c|}
\hline $\log \mathrm{fO}_{2}$ & $\Delta Q F M$ & $\begin{array}{l}\mathrm{Fe}^{3+} / \mathrm{Fe}^{\mathrm{TOT}} \\
\text { Mössbauer }\end{array}$ & Int. & Mix. & A.M. & N.N. & K.R. & S.V. \\
\hline 4.8 & 11.2 & 1.000 & 1.01 & 0.99 & 1.01 & 0.97 & 1.00 & 0.97 \\
\hline 0.00 & 6.38 & 0.773 & 0.75 & 0.73 & 0.75 & 0.77 & 0.77 & 0.75 \\
\hline-1.00 & 5.40 & 0.661 & 0.66 & 0.63 & 0.65 & 0.66 & 0.66 & 0.66 \\
\hline-2.00 & 4.40 & 0.537 & 0.53 & 0.51 & 0.53 & 0.54 & 0.54 & 0.54 \\
\hline-3.07 & 3.32 & 0.414 & 0.43 & 0.42 & 0.43 & 0.43 & 0.42 & 0.44 \\
\hline-4.00 & 2.39 & 0.250 & 0.26 & 0.25 & 0.27 & 0.23 & 0.27 & 0.28 \\
\hline-5.00 & 1.39 & 0.167 & 0.16 & 0.15 & 0.16 & 0.14 & 0.16 & 0.17 \\
\hline-6.00 & 0.39 & 0.103 & 0.11 & 0.10 & 0.11 & 0.09 & 0.10 & 0.10 \\
\hline-7.00 & -0.61 & 0.039 & 0.01 & 0.01 & 0.01 & 0.05 & 0.04 & 0.05 \\
\hline-8.00 & -1.61 & 0.024 & 0.04 & 0.04 & 0.05 & 0.04 & 0.03 & 0.02 \\
\hline-9.00 & -2.61 & 0.017 & 0.02 & 0.00 & 0.01 & 0.03 & 0.02 & 0.01 \\
\hline-10.00 & -3.61 & 0.000 & 0.00 & 0.00 & -0.01 & 0.02 & 0.01 & -0.01 \\
\hline-11.00 & -4.61 & 0.000 & 0.01 & 0.03 & 0.01 & 0.01 & 0.00 & 0.01 \\
\hline & & RMSD: & 0.02 & 0.03 & 0.03 & $\begin{array}{l}0.01^{*} \\
0.04^{\phi}\end{array}$ & $\begin{array}{l}0.01^{*} \\
0.02^{\phi}\end{array}$ & $\begin{array}{l}0.02^{*} \\
0.03^{\phi}\end{array}$ \\
\hline
\end{tabular}


830 Figure 1: Raman spectra of synthetic MORB basaltic glasses; the colors indicate $\mathrm{Fe}^{3+} / \mathrm{Fe}^{\mathrm{TOT}}$.

831 Each spectrum corresponds to the mean of five spectra acquired for each sample. The dashed

832 lines labelled A-G mark the position of peaks and shoulders (see text).

834 Figure 2: A) Example of the treatment of the $800-1300 \mathrm{~cm}^{-1}$ sections of the Raman spectra that 835 was performed prior to any calculation. The linear cut-off baseline (red dotted line) joins the 836 sample signals at 850 and $1140 \mathrm{~cm}^{-1}$. Any intensity below this baseline was removed from the 837 data. B) Intensity from $850-1140 \mathrm{~cm}^{-1}$ after baseline subtraction. This background subtracted region of the spectra was normalised between 0 and 1 .

840 Figure 3: Normalised intensity at $930 \mathrm{~cm}^{-1}$ in the Raman spectra of the glasses as a function 841 of the oxidation state of Fe. The line is a linear fit to the data. If not visible, errors are smaller 842 than the symbols.

844 Figure 4: A) Comparison of the mean spectrum at $\mathrm{Fe}^{3+} / \mathrm{Fe}^{\mathrm{TOT}}=0.41$ (black line) and the fit 845 (dotted red line) as a linear combination of the oxidised ( $\left.\mathrm{S}_{\mathrm{OXX}}\right)$ and reduced $\left(\mathrm{S}_{\mathrm{RED}}\right)$ spectra 846 (Mixing method); residuals between the data and fit are shown in the bottom panel. B) Fraction 847 of the oxidised endmember spectrum, $F_{\mathrm{OXX}}$, as a function of the oxidation state of $\mathrm{Fe}$ in the 848 glasses. The line is a linear fit to the data. If not visible, errors are smaller than the symbols.

850 Figure 5: Contour plots of the root-mean-square deviations (RMSD) between the measured $851 \mathrm{Fe}^{3+} / \mathrm{Fe}^{\text {TOT }}$ values and those predicted using the $A L S M C R$ algorithm using (A) variable training 852 subsets $D_{n, m}$ and (B) different initial $S_{k, m}$ spectra. In (A), RMSD $\mathrm{Fe}^{3+} / \mathrm{Fe}^{\mathrm{TOT}}$ are represented 853 against the mean and the range of $\mathrm{Fe}^{3+} / \mathrm{Fe}^{\text {TOT }}$ values in the data subsets used to train the 854 algorithm. In (B), they are represented against the mean and the range of $\mathrm{Fe}^{3+} / \mathrm{Fe}^{\mathrm{TOT}}$ between 855 the two initial $\mathrm{S}$ spectra used to initiate the training. After training, RMSD Fe ${ }^{3+} / \mathrm{Fe}^{\mathrm{TOT}}$ were 856 estimated on the entire dataset. Black points show where calculations were made; lines and 857 colors were obtained by triangular interpolation.

859 Figure 6: Results of the $A L S M C R$ algorithm using the entire $D_{n, m}$ dataset, with initial (init.) $860 S_{k, m}$ spectra at $\mathrm{Fe}^{3+} / \mathrm{Fe}^{\mathrm{TOT}}=0.66$ and 0.25 . A) Initial (init.) and optimised (opt.) oxidised $\left(S_{\mathrm{Ox}}\right)$ 861 and reduced $\left(S_{\text {RED }}\right)$ endmember spectra; residuals between the optimised $S_{\mathrm{OX}}$ and $S_{\text {RED }}$ 862 components and the means of spectra recorded for samples with $\mathrm{Fe}^{3+} / \mathrm{Fe}^{\mathrm{TOT}}=0$ and 1 are shown 863 in the bottom panel. B) Comparison of the mean spectrum at $\mathrm{Fe}^{3+} / \mathrm{Fe}^{\mathrm{TOT}}=0.41$ (black line) and 
864 its fit (dotted red line) obtained by mixing the $S_{\text {Ox }}$ and $S_{\text {RED }}$ endmembers; residual shown in the

865 bottom panel. C) The fraction of the oxidised end-member, $C_{O X}$, against the $\mathrm{Fe}^{3+} / \mathrm{Fe}^{\mathrm{TOT}}$ values

866 determined by Mössbauer spectroscopy for the MORB glass standards. The line is a linear fit

867 to the data. If not visible, errors are smaller than the symbols.

869 Figure 7: Raman $\mathrm{Fe}^{3+} / \mathrm{Fe}^{\text {TOT }}$ against Mössbauer $\mathrm{Fe}^{3+} / \mathrm{Fe}^{\mathrm{TOT}}$ values for the MORB glass 870 standards. Raman values were obtained from the A) Kernel Ridge, B) Support Vector, and C)

871 Neural Network algorithms. See Table 1 for root-mean-square deviations of each dataset. If 872 not visible, errors are smaller than the symbols.

874 Figure 8: A) Normalised baseline-subtracted Raman spectra of 42 natural MORB glasses (see 875 Supplementary Materials). The red dotted line is the spectrum of the glass standard with $876 \mathrm{Fe}^{3+} / \mathrm{Fe}^{\mathrm{TOT}}=0.10(1)$. B) $\mathrm{I} 930$ as a function of the concentration of $\mathrm{MgO}+\mathrm{CaO}(\mathrm{wt} \%)$ in the 877 glasses.

879 Figure 9: $\mathrm{I}_{930}$ as a function of the mean ionic field strength of modifier cations, IFS(M) for 880 natural MORB glasses (open symbols) and MORB standards (solid symbols). Dotted lines 881 represent the values of the model (eq. 6, see text) that links $\mathrm{I}_{930}$ to IFS(M) and $\mathrm{Fe}^{3+} / \mathrm{Fe}^{\mathrm{TOT}}$ in 882 MORB glasses. The colors reflect the $\mathrm{Fe}^{3+} / \mathrm{Fe}^{\mathrm{TOT}}$ ratio (see colorbar).

884 Figure 10: Neural network predicted versus measured compositions of natural MORB glasses.

885 The standard deviations between the measured and predicted values for each subset are given 886 for each compositional component. 


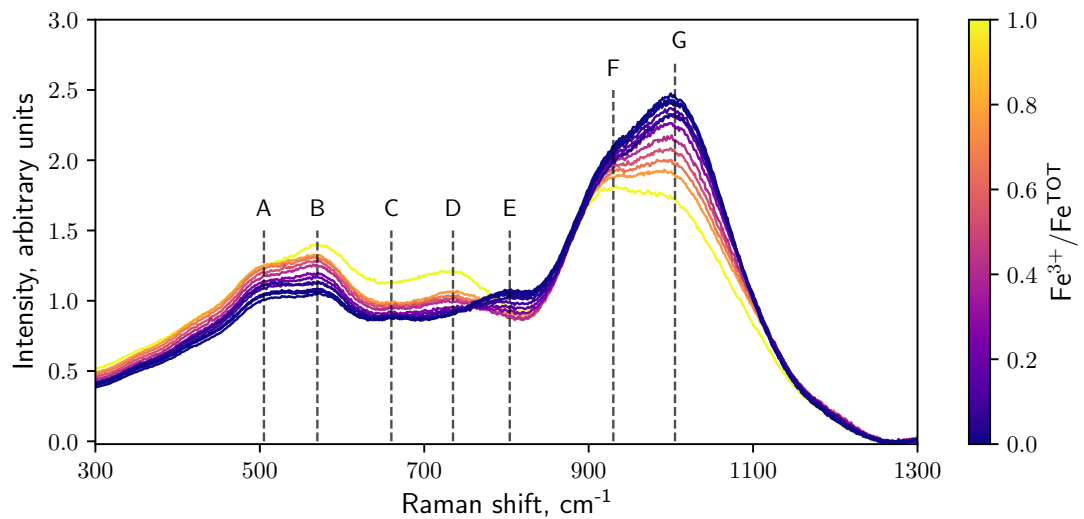



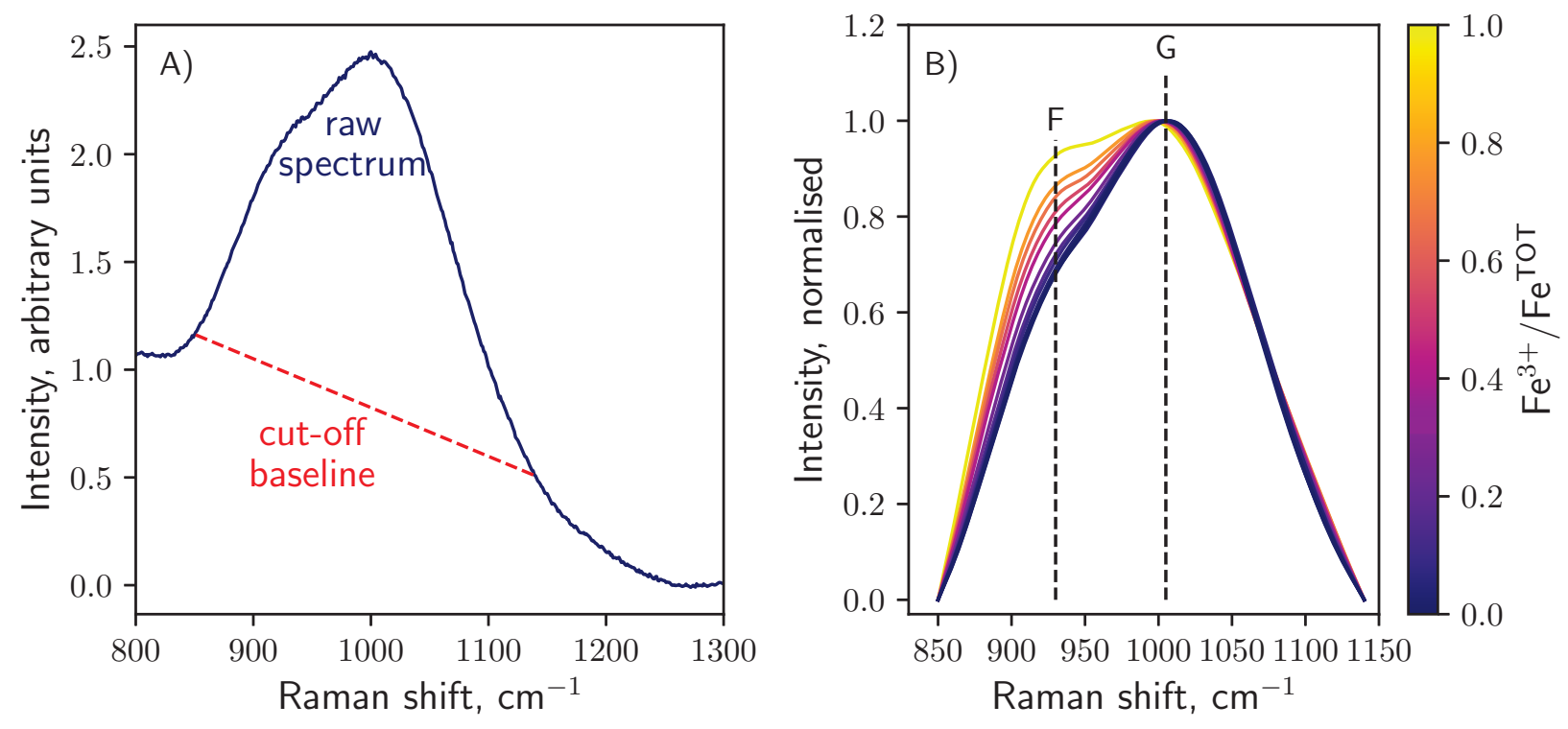


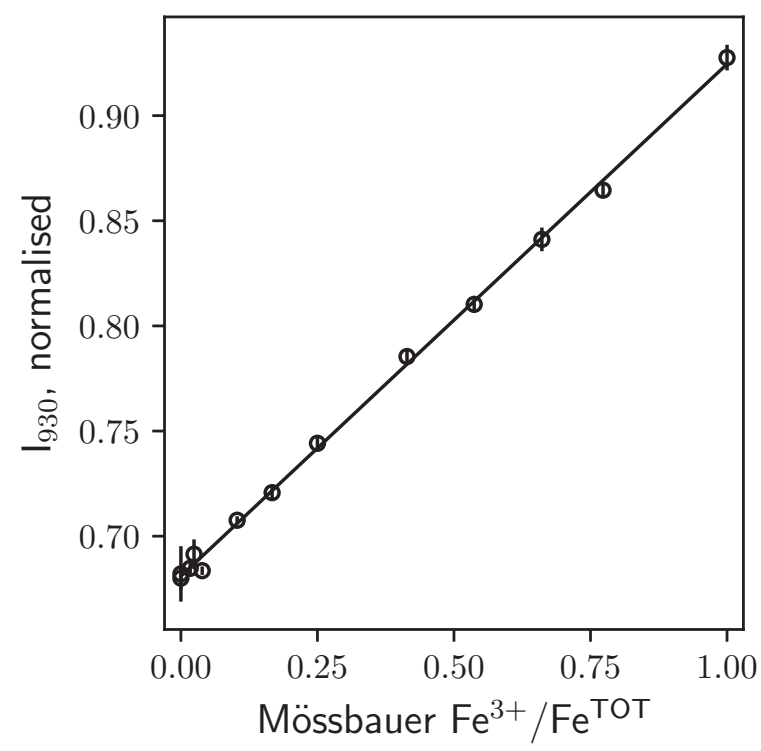



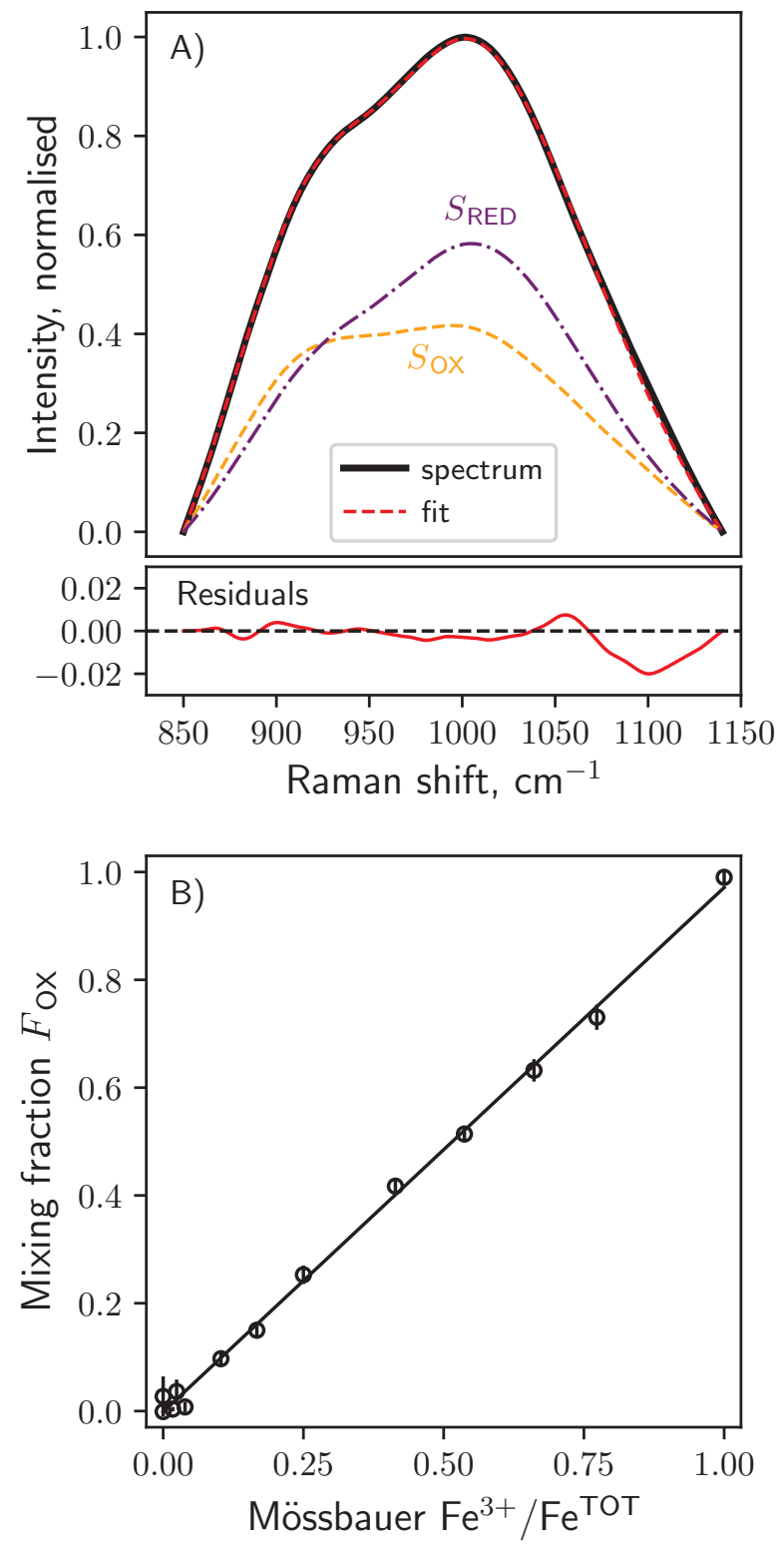


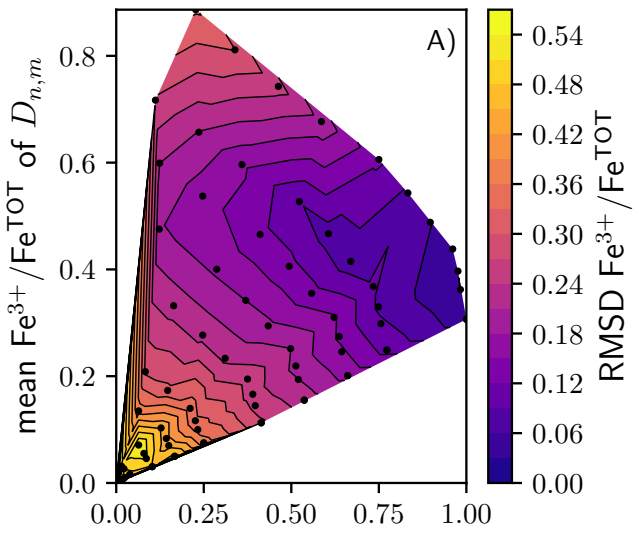

$\Delta \mathrm{Fe}^{3+} / \mathrm{Fe}^{\mathrm{TOT}}$ of $D_{n, m}$

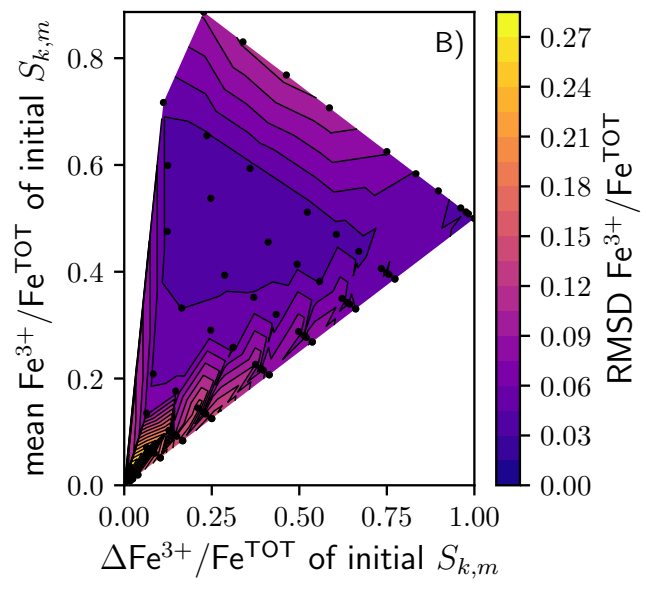



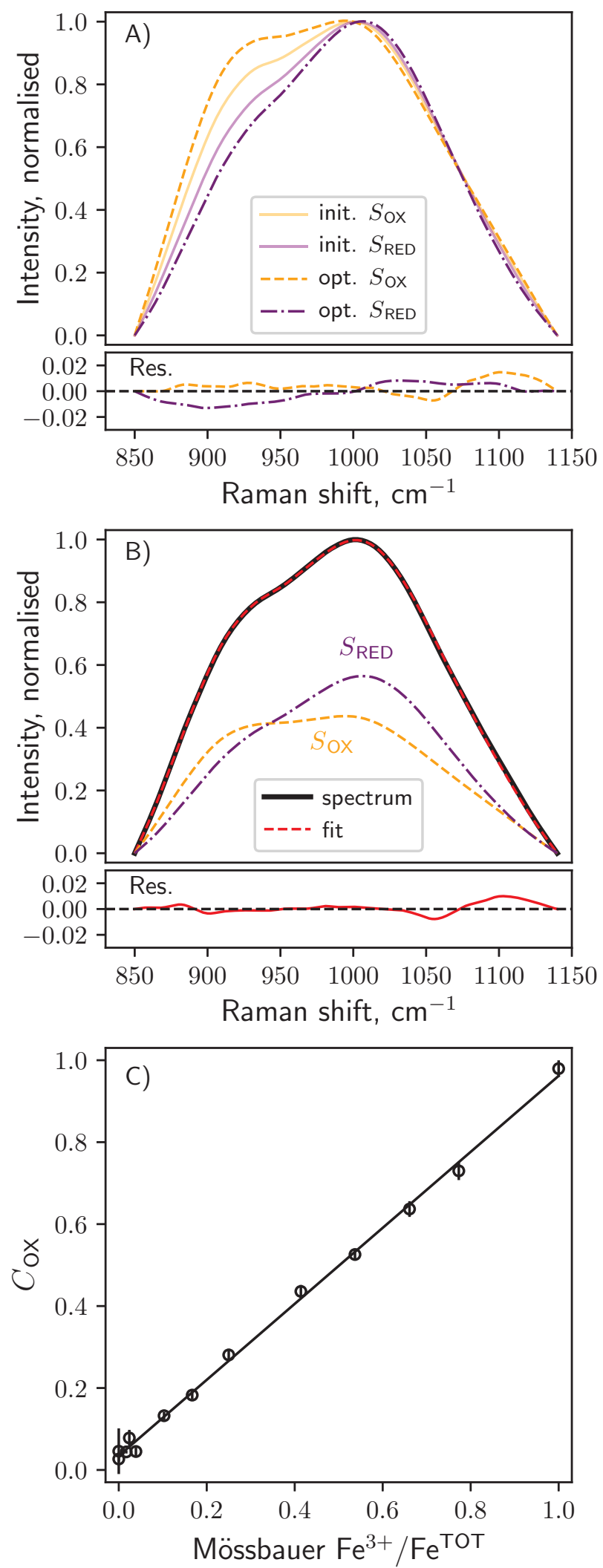

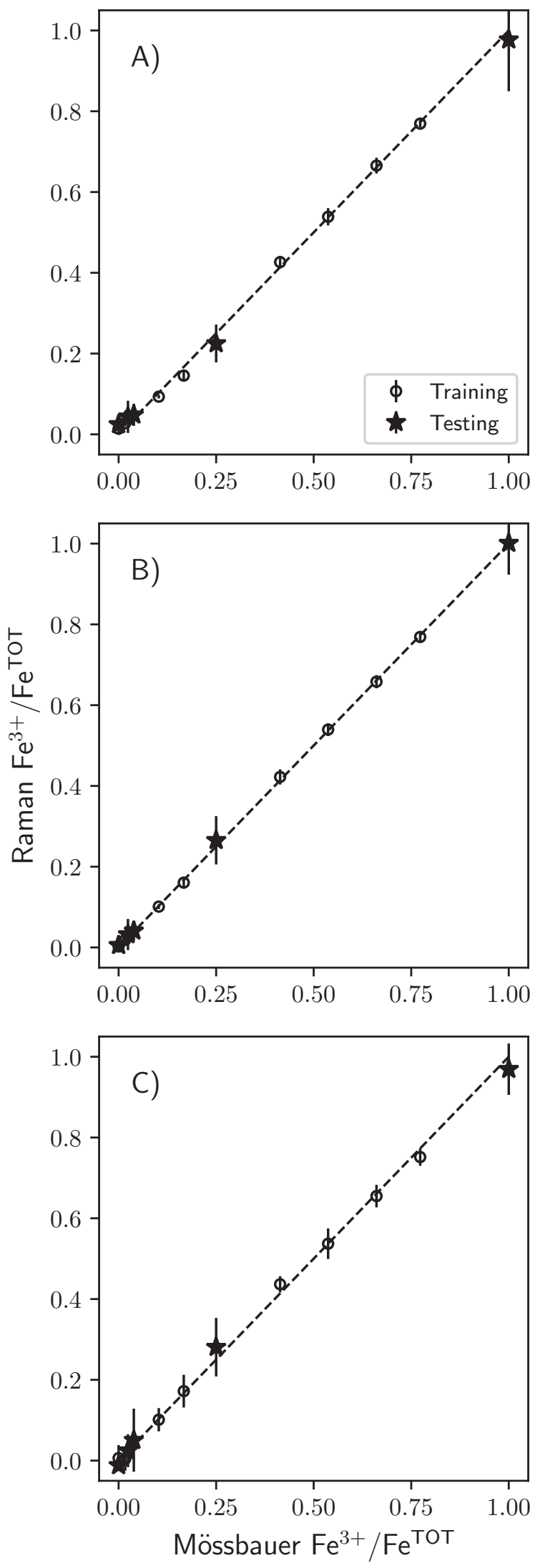

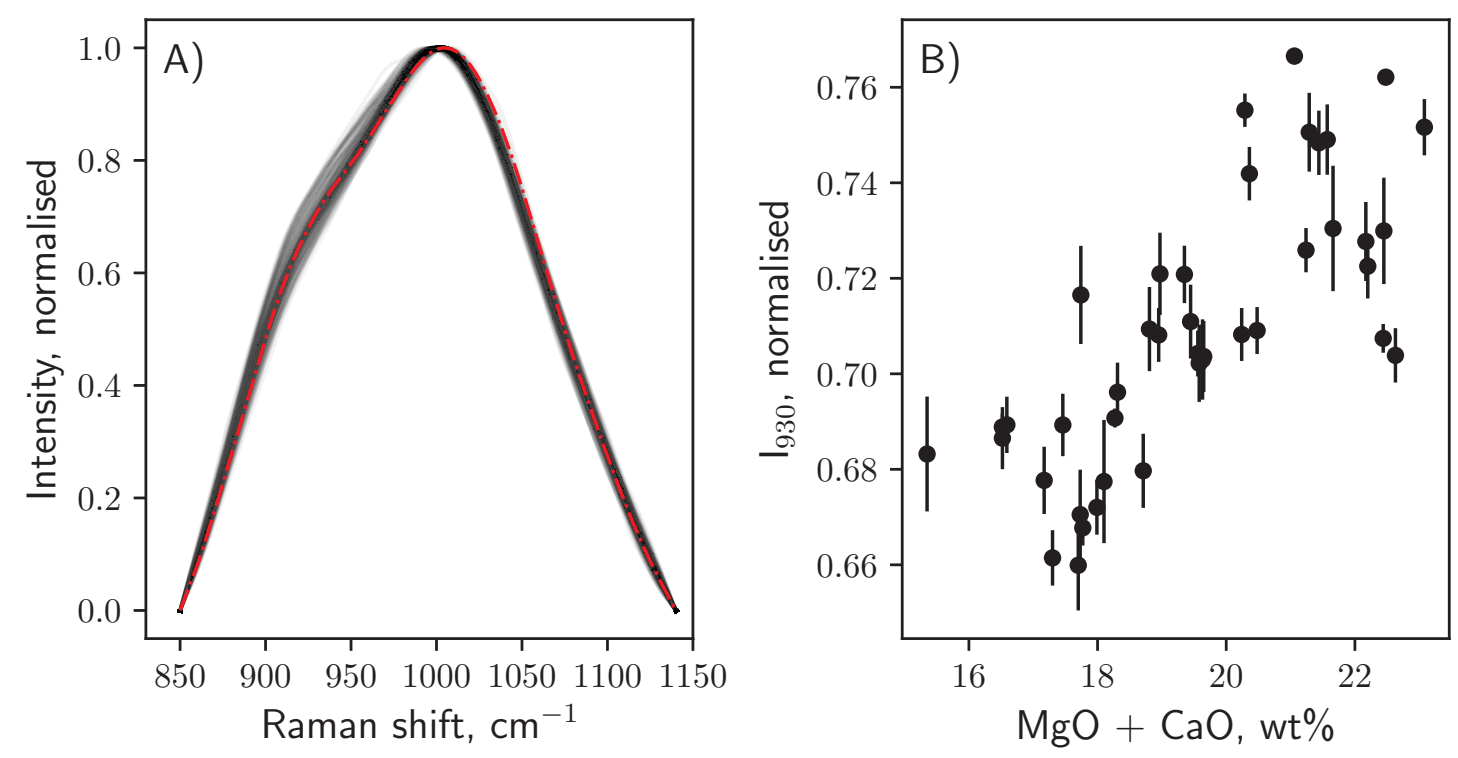


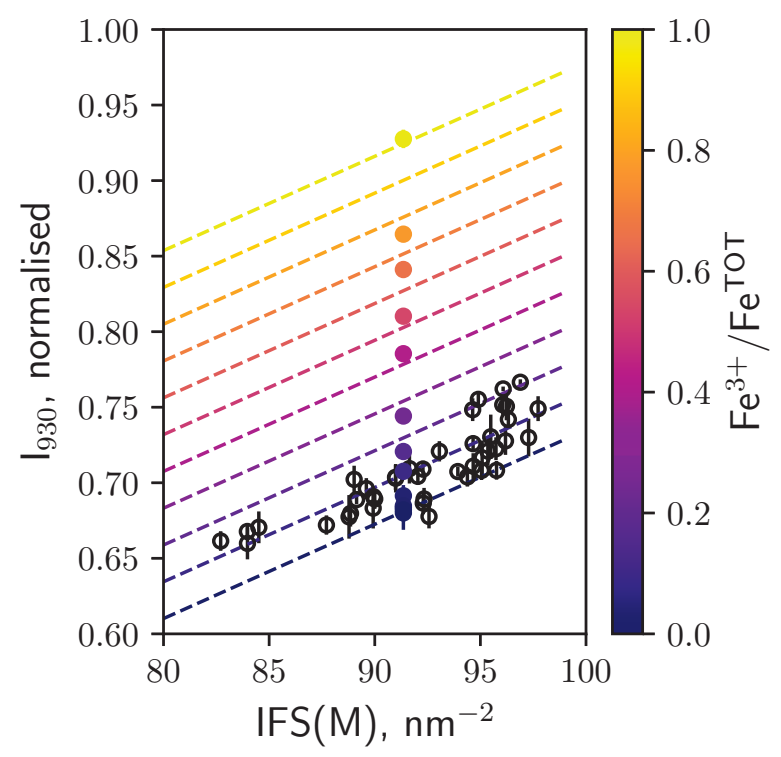



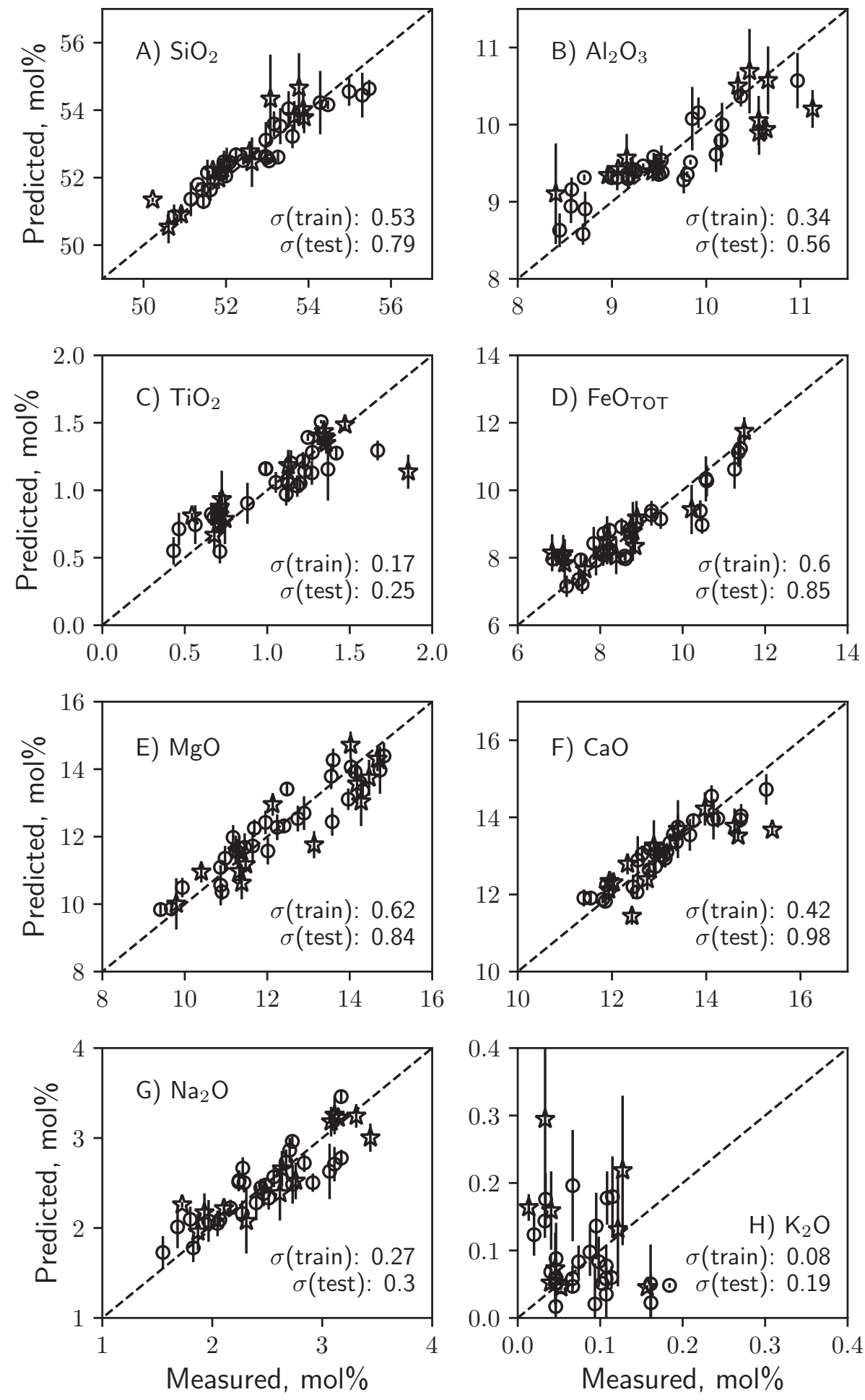